\title{
1 A volumetric technique for fossil body mass estimation applied to Australopithecus
}

2 afarensis

3

4 Charlotte A. Brassey ${ }^{\mathrm{a}, *++}$, Thomas O'Mahoney ${ }^{\mathrm{b},+}$, Andrew T. Chamberlain $^{\mathrm{b}}$, William I.

5 Sellers $^{b}$

6

7 aschool of Science and the Environment, Manchester Metropolitan University, Chester

8 Street, Manchester, M1 5GD, UK

9 bschool of Earth and Environmental Sciences, University of Manchester, Oxford Road,

10 Manchester, M13 9PT, UK

11

12 *Corresponding author; c.brassey@mmu.ac.uk

13 'These authors contributed equally to this work

14

15

16 Keywords: Lucy; reconstruction; convex hull; hominin; primate; 


\section{Abstract}

18 Fossil body mass estimation is a wellestablished practice within the field of physical anthropology. Previous studies have relied upon traditional allometric approaches, in which the relationship between one/several skeletal dimensions and body mass in a range of modern taxa is used in a predictive capacity. The lack of relatively complete skeletons has thus far limited the potential application of alternative mass estimation techniques, such as

23 volumetric reconstruction, to fossil hominins. Yet across vertebrate palaeontology more

24 broadly, novel volumetric approaches are resulting in predicted values for fossil body mass very different to those estimated by traditional allometry. Here we present a new digital reconstruction of Australopithecus afarensis (A.L. 288-1; 'Lucy') and a convex hull-based volumetric estimate of body mass. The technique relies upon identifying a predictable relationship between the 'shrink-wrapped' volume of the skeleton and known body mass in a range of modern taxa, and subsequent application to an articulated model of the fossil taxa of interest. Our calibration dataset comprises whole body computed tomography (CT) scans of 15 species of modern primate. The resulting predictive model is characterized by a high correlation coefficient $\left(r^{2}=0.988\right)$ and a percentage standard error of $20 \%$, and performs well when applied to modern individuals of known body mass. Application of the convex hull technique to $A$. afarensis results in a relatively low body mass estimate of $20.4 \mathrm{~kg}(95 \%$ prediction interval $13.5-30.9 \mathrm{~kg}$ ). A sensitivity analysis on the articulation of the chest region highlights the sensitivity of our approach to the reconstruction of the trunk, and the incomplete nature of the preserved ribcage may explain the low values for predicted body mass here. We suggest that the heaviest of previous estimates would require the thorax to be expanded to an unlikely extent, yet this can only be properly tested when more complete fossils are available. 


\section{Introduction}

Body mass is a critical constraint on an organism's ecology, physiology, and

biomechanics, and is a required input parameter in many ecological and functional analyses.

For paleontologists, it is thus highly desirable to reconstruct body mass for fossil species.

Indeed, important studies concerning the evolution of brain size (McHenry, 1976), locomotor kinematics (Polk, 2004), and energetics (Steudel-Numbers, 2006) in hominins have all required reliable fossil body mass estimates.

The fossil record is, however, extremely fragmentary and the majority of specimens are known only from isolated elements. For this reason, the most common approach to mass estimation exploits a tight correlation between body mass and a given skeletal dimension or dimensions in a modern calibration dataset to derive a predictive equation. Within the field of physical anthropology, cranial metrics have been used in a predictive capacity, including orbital area (Kappelman, 1996), orbital height (Aiello and Wood, 1994), and facial breadth (Spocter and Manger, 2007). However, far more common are mass prediction equations based on postcranial elements, which Auerbach and Ruff (2004) subdivide into 'mechanical' and 'morphometric' methods on the basis of the chosen skeletal element. Mechanical techniques employ postcranial, mass supporting structures as a basis for predictive equations, including knee breadth (Squyres and Ruff, 2015), vertebral centrum area (McHenry, 1976), femoral head and neck breadth (Ruff et al., 1991), and humeral and radial head diameter (McHenry, 1992). Alternatively, morphometric techniques reconstruct fossil mass based on the direct assessment of body size and shape. For example, a series of studies (Ruff, 1994, 2000; Ruff et al., 2005) have found the combination of stature and biiliac breadth to provide relatively accurate estimates of body mass when applied to modern humans. Footprint area (as measured from fossil trackways) has even been used as a means of reconstructing hominin body mass (Dingwall et al., 2013, Masao et al., 2016).

Whilst bivariate and multivariate mass predictive equations benefit from their applicability to fragmentary material and the ability to generate large modern comparative datasets, there 
are associated disadvantages: which skeletal element to use, extrapolation, biasing by robust/gracile elements, and mass and inertia properties.

Which skeletal element to use?

When numerous skeletal elements are available for a particular fossil individual, it may be unclear which bony dimension ought to be used as a basis for mass prediction. If both a complete femur and tibia are available, for example, either could be considered a suitable mass-supporting structure upon which to base a fossil mass estimate. Yet previous research estimating body mass for non-primate fossil mammals demonstrates that estimates can span two orders of magnitude for the same individual depending on which limb bone or skeletal metric was used for prediction (Fariña et al., 1998). This example includes unusually proportioned mammals such as xenarthrans, and mass estimates for fossil hominins are not known to vary to such a degree (e.g., McHenry's 1992 estimates for the Australopithecus afarensis skeleton A.L. 288-1 based on different anatomical parts range between 11.8 and $37.1 \mathrm{~kg}$ ). However, McHenry and Berger (1998) do highlight the potential for hominin mass estimates to vary considerably depending upon the use of forelimb or hind limb joint size as the basis for the predictive equation. Ultimately, a decision must still be made on which equation to use, taking into account the predictive power of the model $\left(r^{2}\right.$ or percentage prediction error) and the existence of taphonomic damage or unusual morphology, for example, that may otherwise bias the result.

\section{Extrapolation}

Whilst typically less extreme in paleoanthropology compared to other disciplines of vertebrate paleontology, body mass estimations are often conducted on fossil specimens lying outside the range of body sizes occupied by the modern calibration dataset. Potential dwarfism (Brown et al., 2004, Vančata, 2005, Holliday and Fransiscus, 2009, Stein et al., 2010; Herridge and Lister, 2012) and gigantism (Millien and Bovy, 2010; Bates et al., 2015) are recurrent themes for fossil mass reconstructions, yet by their very nature they require an 
extrapolation of a predictive relationship beyond the modern range. In such instances, extrapolated predictions should be regarded as extremely speculative (Smith, 2002) due to a lack of evidence that the linear model holds beyond the extant dataset and a rapid widening of confidence intervals around the prediction.

\section{Biasing by robust/gracile elements}

Underlying the theory of bivariate/multivariate mass prediction is the assumption that the relationship between mass and a given skeletal dimension identified in modern species also holds for the fossil species of interest. In some instances, however, we can intuitively appreciate that species may be characterized by unusually proportioned skeletal elements (the elongated canines of sabretoothed cats, or the robust hind limb bones of some dinornithiform birds for example). When placed into the context of the rest of the body, such enlarged/reduced features are obvious. Should such structures be used as a basis for mass estimation, however, unfeasibly large/small fossil species will be reconstructed (Braddy et al., 2008 vs. Kaiser and Klok, 2008, Brassey et al., 2013). This is a particular concern when dealing with isolated elements in the absence of complete skeletons, where relative robustness/gracility cannot be known. In physical anthropology, for example, the mass estimation of Gigantopithecus on the basis of molar size (Conroy, 1987) or mandible size (Fleagle, 2013) is vulnerable to this problem.

\section{Mass and inertia properties}

Currently, traditional allometric predictive relationships produce a solely scalar value for body mass (i.e., $X$ species weighed $Y \mathrm{~kg}$ ). Whilst these single values may be of use in subsequent ecological analyses or evolutionary models, they are not informative with regards to how said mass is distributed around the body. Inertial properties (including mass, center of mass, and moments of inertia) are essential when conducting biomechanical simulations such as multibody dynamic analyses of locomotion and feeding. Previous biomechanical analyses of fossil hominins have therefore reconstructed inertial parameters 
125 on the basis of modern human and chimpanzee values (Crompton et al., 1998; Kramer and

126 Eck, 2000; Sellers et al., 2004), due to a lack of viable alternatives.

\section{Volumetric techniques}

128 For the above reasons, volumetric mass estimation techniques have become

129 increasingly popular within the field of vertebrate paleontology (see Brassey, 2017 and

130 references therein). Historically, volume based estimates required the sculpting of scale

131 models and the estimation of volume via fluid displacement (Gregory, 1905; Colbert, 1962;

132 Alexander, 1985). However, as part of the recent shift towards 'virtual paleontology' (Sutton

133 et al., 2014; as characterized by the increased application of digital imaging techniques such

134 as computed tomography, laser scanning, and photogrammetry), three-dimensional (3D)

135 computational modeling of fossil species is becoming increasingly common. As articulated

136 skeletons are digitized faster and with greater accuracy, volumetric mass estimation

137 techniques now involve the fitting of simple geometric shapes (Gunga et al., 1995, 1999) or

138 more complex contoured surfaces (Hutchinson et al., 2007; Bates et al., 2009) to digital

139 skeletal models within CAD (computer-aided design) packages. Volumetric approaches

140 overcome many of the limitations associated with traditional allometric mass estimation

141 methods, including the need to extrapolate predictive models and rely upon single elements,

142 whilst also allowing inertial properties to be calculated if desired.

143 Both physical sculpting and digital CAD 'sculpting' of 3D models inevitably involves

144 some degree of artistic interpretation, however. By attempting to reconstruct the external

145 appearance of an extinct species, assumptions must be made regarding the volume and

146 distribution of soft tissues beyond the extent of the skeleton. Whilst those undertaking said

147 modeling necessarily rely upon their experience as anatomists to inform reconstructions,

148 previous research has found resulting mass estimates to be sensitive to the individual

149 carrying out the procedure (Hutchinson et al., 2011). The convex hulling technique applied in

150 the present paper was therefore developed with the aim of incorporating many of the

151 benefits associated with volumetric mass estimation, whilst overcoming the subjectivity

152 inherent in 'sculpted' models (Sellers et al., 2012). 
A convex hull is a geometric construct commonly used within mathematical sciences.

154 The convex hull of $n$ points is simply the minimum size convex polytope that still contains $n$

155 (Fig. 1). In two dimensions, the process is analogous to stretching an elastic band around 156 the series of points, with the band 'snapping-to' the outermost points. The ultimate form of 157 the hull is dictated by a small number of points lying at the extremities and for a given set of 158 points there is a unique convex hull. Two-dimensional (2D) convex hulls have often been 159 applied in ecology as a means of defining the range size of wild animals (Harris et al., 1990

160 and references therein) or quantifying population niche width around stable isotopic data

161 (Syväranta et al., 2013). A 3D convex hull can, likewise, be fitted to a suite of $x, y, z$

162 coordinates to form a tight-fitting 3D polyhedron (Fig. 2). Three-dimensional convex hulls are more commonly applied within the fields of robotics and computer games design to rapidly detect potential collisions between objects (Jiménez et al., 2001), but have also been applied in the biological sciences to estimate volume of crop yield (Herrero-Huerta et al., 2015) or canopy foliage (Cheein and Guivant, 2014).

Sellers et al. (2012) initially developed the convex hull mass prediction technique on a dataset of modern quadrupedal mammals. Using a LiDAR (light detection and range) scanner, the articulated skeletons of 14 mammals located within the main gallery of the Oxford University Museum of Natural History (OUMNH) were digitized. Point clouds corresponding to individual skeletons were isolated from the larger gallery scan and each skeleton subdivided into functional units (e.g., head, neck, thigh, shank, and trunk). Convex

173 hulls were fitted to the point clouds representing all functional units, and the total convex hull 174 volume of the skeleton was calculated as the sum of individual segments (Fig. 2). Total convex hull volume was subsequently multiplied by a literature value for body density to produce a convex hull mass and regressed against body mass to produce a linear bivariate predictive equation. The model was characterized by a high correlation coefficient and percentage standard error of the estimate (\%SEE) of approximately $20 \%$. In some respects, convex hulling is a hybrid technique, combining volumetric data

180 from an articulated skeletal model with the more traditional allometric mass estimation 
approach. By incorporating data from the entire skeleton, the technique may be less

182 sensitive to particularly robust or gracile elements than previous approaches, and no

183 decision need be made regarding which particular bone to base estimates upon. As a

184 volumetric technique, convex hulling may also provide values for segment inertial properties

185 whilst avoiding the subjectivity inherent within previous sculpting techniques. The initial

186 Sellers et al. (2012) application of convex hulling did, however, require a literature value for

187 body density to be assigned to the modern dataset, which was itself heavily dominated by

188 ungulates.

189 Subsequent applications of the convex hulling procedure have sought to overcome some of

190 the above concerns. Brassey et al. (2014) directly regressed convex hull volume against

191 body mass to generate scaling equations for both mammals (including primates) and birds,

192 without the requirement to assign a literature value for body density. There is an inherent

193 assumption, however, that the body density of the fossil species falls within the range of

194 values occupied by the modern taxa. Furthermore, Brassey et al. $(2013,2016)$ produced

195 additional convex hull predictive equations based upon modern ratites and pigeons for

196 application to the mass estimation of the extinct moa and dodo, respectively.

Mass estimation of Australopithecus afarensis (A.L. 288-1)

The partial Australopithecus afarensis skeleton A.L. 288-1 ('Lucy') is one of the most complete Pliocene hominin skeletons found to date, with over $40 \%$ of the skeleton preserved, including the pelvis and most of the upper and lower limbs represented by at least one side (Johansen and Edey, 1981; Johanson et al., 1982). The only other $A$. afarensis remains approaching such percentage preservation is the Woranso-Mille specimen (Haile Selassie et al., 2010), with other relatively complete specimens including the Australopithecus sediba remains from Malapa (Berger et al., 2010) and the 'Little Foot' skeleton, attributed to Australopithecus prometheus (Clarke, 1998). Unsurprisingly, A.L. 288years (Fig. 3). 
Due to the relative completeness of the specimen, previous mass estimates of A.L.

210 288-1 have been based upon axial, sacral, forelimb, and hind limb elements, and indeed

211 multivariate models incorporating several elements. Table 1 details the results of McHenry's

212 (1992) often-cited study, in which the body mass of A.L. 288-1 was estimated on the basis of

213 several skeletal elements using both an ape- and human-based predictive equation. As can

214 be seen in Table 1, estimated body mass ranged between 13 and $37 \mathrm{~kg}$ within a single study

215 (based on the radial head and femoral shaft respectively). More broadly, across the gamut of

216 previous mass estimates for A.L. 288-1(including predictive intervals when calculated),

217 published values range from 13 to $42 \mathrm{~kg}$ (Fig. 3), with studies diverging in their choice of

218 reference dataset, skeletal metric, and Type I versus Type II regressions. It should be noted,

219 however, that the mass estimates in Figure 3 represent the extreme upper and lower values

220 of each publication and do not account for any author preference stated with regards to which estimate is most appropriate. McHenry (1992) favors the human-based predictive equation for example, narrowing the range to $17-37 \mathrm{~kg}$. Likewise, Squires and Ruff (2015) present results from both Type I and Type II regressions, but consider the results of the ordinary least squares (OLS) analysis inappropriate and favor reduced major axis (RMA). Yet despite three decades' worth of debate regarding the appropriate choice of skeletal element, dimension, modern calibration dataset, and regression type, Figure 3 suggests most studies do indeed overlap in the area of $25-37 \mathrm{~kg}$.

Although A.L. 288-1 has frequently been the subject of fossil hominin mass prediction studies, a volumetric reconstruction has never been attempted. Numerous

230 dynamic analyses of locomotion in $A$. afarensis have required values for center of mass and 231 segment inertial properties for the specimen (Crompton et al., 1998; Kramer, 1999; Kramer and Eck, 2000; Sellers et al., 2004; Wang et al., 2004; Nagano et al., 2005; Sellers et al., 2005). In all instances, however, body mass has been assigned a priori on the basis of previously published estimates, with the mass subsequently distributed around the skeleton via scaling of human and/or chimpanzee inertial properties. The slow adoption of volumetric mass estimation in physical anthropology compared to other paleontological disciplines 
237 (Brassey et al., 2017) may be attributed partly to the relative paucity of complete skeletons.

238 Whilst A.L. 288-1 is indeed one of the most complete Pliocene hominins ever found, large

239 portions of the skeleton were not recovered. Most notably, the vertebral column and

240 shoulder girdle is poorly represented, with considerable portions missing. The rib cage is

241 relatively well represented, with material available for all ribs barring ribs 2 and 12 . Due to

242 the fragmentary nature of the costal remains, a good deal of reconstruction and interpolation

243 is required however. This is particularly problematic when conducting volumetric mass

244 estimation, as the vast majority of total body volume resides within the trunk.

245 A volumetric reconstruction of $A$. afarensis A.L. 288-1 is a worthwhile endeavor on

246 several grounds. Recent studies of non-hominin fossil skeletons have found traditional

247 bivariate mass predictions to be unfeasibly high (Brassey et al., 2013; Bates et al., 2015),

248 but such insight may only be gained via attempting to fit volumetric shapes around the

249 skeleton to simulate the extent of soft tissue required to achieve said mass values. Whilst

250 the wealth of pre-existing mass estimates of A.L. $288-1$ is commendable, they are heavily

251 skewed towards hind limb and pelvis based regressions. Although this may be justifiable on

252 mechanical grounds, it would seem prudent to also approach the problem of mass

253 estimation from an alternative and innovative direction incorporating information from across

254 all available skeletal material.

As a volumetric technique, convex hulling is well suited to the reconstruction of specimens characterized by incomplete thoracic material. The extent of an object's convex

257 hull is dictated by its geometric extremes (Fig. 1), ensuring the presence of 'missing data'

258 within the bounds of the hull does not impact upon its ultimate volume. As such, absence of

259 or damage to vertebrae or ribs lying within the bounds of the 'trunk' functional unit will not

260 negatively impact resulting mass estimates. A corollary, however, is this makes it even more

261 essential that the placement of geometric extremes (and any additional spacing to account

262 for missing elements) is reliable.

263 In this paper, we use convex hulling to estimate the body mass of the (reconstructed)

264 A.L. 288-1 skeleton. In doing so, we also explore the effect of uncertainty in the articulation 
of the thorax and reconstruction of the pelvis on resulting mass estimates. In the past, the

266 form of the $A$. afarensis ribcage has been debated, typically falling into a dichotomy of an

267 ape-like 'funnel shape' versus human-like 'barrel shape' (Latimer et al., 2016 and references therein). Despite this interest, relatively little is known of the effect thoracic morphology may have upon resulting mass estimates and inertial properties. The novel application of convex hulling to the mass estimation of $A$. afarensis will act as an independent check on the validity of previous allometry based mass predictions and going forward will further inform discussions on the nature of australopith locomotion and sexual dimorphism that are themselves heavily reliant upon values for body mass. convex hulling methodology. In doing so, we accompany our mass estimates with the most transparent and rigorous 3D reconstruction of A.L. 288-1 to date. We aim to equip the reader with the methodological tools necessary to expand this technique, as well as a grounding in its current benefits and limitations. Given the ongoing discovery of exceptional specimens and the rapidly declining costs of digitization, we are optimistic that this technique can be more broadly applied within the field of human evolution. Of course, this will be facilitated by a shift towards authors making underlying digital datasets freely available (Davies et al., 2017), a practice from which we all stand to benefit greatly.

\section{Materials and methods}

Modern calibration dataset

There is considerable debate in the literature regarding the appropriate choice of reference population when applying predictive equations to fossil hominins. Typically, calibration datasets comprise modern humans, modern human populations of small stature, African great apes, (Jungers, 1990; Hens et al., 2000; Grabowski et al., 2015) or a combination of the above. When deriving mass prediction equations based on hind limb

291 dimensions, human based models are often preferred due to a perceived similarity in limb

292 function, i.e., potential bipedalism. This, in itself, requires an a priori assumption of the fossil 
293 taxa being bipedal, an issue that is particularly problematic should the derived body mass

294 subsequently be used in biomechanical analysis of potential bipedalism. Alternatively, a

295 training dataset comprising modern human populations of small stature might be preferred to

296 minimize the degree of extrapolation necessary from smallest modern individual to fossil

297 taxa. But again, this involves an assumption of fossil hominin body size (i.e., lying below that

298 of most modern individuals) prior to the analysis (Konigsberg et al., 1998).

299 Given the paucity of available whole body CT data, a convex hull predictive model

300 based solely on modern humans is currently difficult to achieve, particularly in the case of

301 humans from small-stature populations. Here, we apply an 'all primate' predictive model to

302 the estimation of $A$. afarensis body mass. In doing so, we make no assumptions regarding

303 the locomotor function of the hind limbs or the range of body sizes probably occupied by $A$.

304 afarensis. By applying an 'all primate' model, we assume there is a consistent relationship

305 between the volume defined by the extremities of the skeleton and total body mass. As an

306 alternative way of conceptualizing this, we assume the volume (and density) of soft tissue

307 distributed outside the bounds of the convex hull to scale to body mass in a predictable

308 manner across all primates, including fossil hominins. As such, the convex hull is

309 conceptually closer to a 'morphometric' rather than 'mechanical' technique as defined by

310 Auerbach and Ruff (2004).

312 Computed tomography The extant dataset comprises 15 species of modern primate (Table

313 2), several of which were included in an initial convex hulling study on extant mammals

314 (Brassey et al., 2014). CT scans of whole carcasses were sourced from the Kyoto University

315 Primate Research Institute (KUPRI, http://dmm3.pri.kyoto-u.ac.jp) and the male human from

316 the Visible Human Project (National Library of Medicine, NLM,

317 www.nlm.nih.gov/research/visible). In the absence of available whole body CT scans from

318 other ethnic groups, the human representative is a non-pathological, white male. Additional

319 carcasses were sourced from the National Museum of Scotland (NMS) and were CT

320 scanned at the University of Liverpool using a Toshiba Aquilion PRIME helical veterinary 
scanner. Slice thickness ranged between 0.5 and $2.7 \mathrm{~mm}$ with pixel spacing of $0.29-0.98$ $\mathrm{mm} /$ pixel, depending on the total size of the animal. articulated skeletons thresholded out on the basis of grayscale values (Fig. 2) and exported as OBJ files. In some instances, cadavers have been subject to postmortem investigations, including the detachment of portions of the cranial vault or sternum. In those cases, the 3D model of the skeleton was digitally repaired and the removed elements realigned and rearticulated in 3ds Max (www.autodesk.com). Skeletal models were subsequently imported into Geomagic Studio (3D Systems, USA) and segmented into functional units (such as head, neck, thigh, trunk; Fig. 2). When present, tails were further subdivided to ensure tight fitting hulls. Individual body segments were saved as OBJ files and convex hulls fitted around the segments using the 'convhulln' function of MATLAB (Mathworks, USA), which implements the qhull algorithm to find the convex hull and return its enclosed volume in minimal computer time (Barber et al., 1996).

336 Statistical analysis Total convex hull volume $\left(\mathrm{m}^{3}\right)$ for each skeleton was calculated as the 337 sum of individual segment volumes. Total convex hull volume was then regressed against known body mass $(\mathrm{kg})$ following $\log _{10}$ transformation in $\mathrm{R}$ (R Core Team, 2014). In two instances, associated body masses were not available (Pan troglodytes, Hylobates lar) and were therefore estimated using a pre-existing bivariate equation based upon radial head surface area in extant hominoids (Ruff, 2003). The effect of including these individuals in the regression analysis is discussed further in the results section. Additionally, several individuals sourced from NMS had, upon inspection of the CT data, been subject to some degree of postmortem surgery in the region of the abdomen, which may have resulted in removal of gut contents and certainly fluid loss. Given that the exact nature of these procedures is unknown, it is not possible to accurately correct cadaveric body mass for

347 these losses. Rather, the regression analyses were rerun excluding these individuals, and

348 the impact on the predictive model is discussed further below. 
350 are recommended when used in a predictive capacity (Smith, 2009), however, results using

351 reduced major axis (RMA) are also included for reference. In addition, a phylogenetic

352 generalized least squares (PGLS) regression was applied to account for the evolutionary

353 non-independence of data points. A consensus phylogeny of primates was downloaded from

354 the 10kTrees website (Arnold et al., 2010) and PGLS analyses conducted in MATLAB using

355 the 'Regressionv2.m' program (Lavin et al., 2008). Raw CT scans of NMS sourced primates

356 have been made available by the authors on figshare (DOI:

357 10.6084/m9.figshare.c.3462618), whilst KUPRI-sourced scans can be accessed online via

358 the Digital Morphology Museum (http://dmm3.pri.kyoto-u.ac.jp) and access to the human

359 dataset can be requested from the Visible Human Project

360 (www.nlm.nih.gov/research/visible).

In addition to the primate carcasses included in the original regression model, supplementary modern specimens of known body mass were subjected to the predictive model in order to test its performance. Six primate scans were sourced from KUPRI, and an additional six CT scans of human males were taken from the National Cancer Imaging Archive (NCIA; Clark et al., 2013; www.cancerimagingarchive.net). The additional CT scans were segmented and processed as above and convex hull based body mass estimates derived using the OLS equation. Furthermore, a "leave-one-out" jackknife analysis of the regression model was conducted, in which one specimen in turn from the original calibration equation was removed and subjected to mass estimation on the basis of the remaining dataset.

Application to fossil material

Casts of the A. afarensis partial skeleton A.L. 288-1 were surface scanned using an LMI HDiR3 Advance structured light scanner (LMI technologies, Delta, BC) at a resolution of approximately $50 \mu \mathrm{m}$. At the time of initial analysis, no $\mu \mathrm{CT}$ data or associated models were publicly available. Subsequently, models of the humerus, scapula fragment, proximal tibia, 
377 and distal femur have been made available from http://www.elucy.org. A deviation analysis

378 of our casts against models based upon said $\mu \mathrm{CT}$ data has shown minimal difference

379 between reconstructions (see Supplementary Online Material [SOM] Figure S1). As such, it

380 was decided to proceed with a model composed predominantly of casts, with the exception

381 of those elements made publicly available by Kappelman et al. (2016) at elucy.org. All

382 'sculpts' were constructed from modelling clay by ATC filling in missing parts of casts without replacing existing cast material. This reconstruction therefore functions as a working hypothesis until access to $\mu \mathrm{CT}$ data of the entire skeleton is freely available. All modern human data referred to here are clinical CT scans from the NCIA, specifically females from the Cetumixab drug trial and Pan troglodytes CT scans from the Arizona primate foundation's skeletal collection (digitized and curated at http://www.carta-anthropogeny.org), with full details of the specimens employed provided in SOM Table S1.

390 Pelvic region The sacrum is crushed, particularly on the left side, and the model was therefore virtually cut in half and the right side mirrored following the protocol outlined in

392 Zollikofer and Ponce de León (2005) and Gunz et al. (2009). In doing so, much of the

393 original distortion was removed, resulting in a marginally wider sacrum than previous

394 reconstructions of Tague and Lovejoy (1986) and Schmid (1983). The complete left os coxa

395 is crushed in the region of the sacroiliac joint and distorted in the ischiopubic region

396 (Johanson et al., 1982). The scanned model was virtually cut into its constituent parts and

397 rearticulated with a concentration on the internal arc being consistent. The complete left os

398 coxa was then articulated to the sacrum with a midline projected from the sacrum, as well as

399 two lines either side at $6 \mathrm{~mm}$ apart to model the length of the ligament for the pubic

400 symphysis. This distance is based on measurements of a small mixed sample of Homo

401 sapiens $(n=8)$ and Pan troglodytes $(n=6)$ medical scans of the pelvic area, where average

402 distance between pubic symphyses was $5.7 \mathrm{~mm}$ with a standard deviation of $\sim 1 \mathrm{~mm}$. Given

403 that there is definitely crushing of the sacroiliac joint in AL288-1 (Johanson et al., 1982; 
404 Williams and Russo 2016, Williams and Russo, 2016), the alignment allows for the eventual

405 restoration of the true joint, as there is also space between our reconstructed sacrum and 406 the pubic symphysis. The resulting articulation of the right os coxa was then mirror-imaged 407 using the midline plane of the sacrum as the reflection plane. The complete pelvis and associated linear metrics can be found in Figure 4, and Tables 3 and 4. A complete 3D model suitable for rapid prototyping is available as supplementary data on Figshare (DOI: 10.6084/m9.figshare.c.3462618, alongside a figure illustrating the reconstruction stages.

Lower limb The left femur is mostly complete, although the distal epiphysis of the original cast was misaligned. The distal epiphysis was therefore virtually rearticulated, along with the proximal fragment that includes the femoral neck and most of the head, to complete the element, ensuring that the dimensions of our scans matched those of the original fossil (Johansen et al., 1982). The length of the incomplete left tibia was estimated using the tibial:humeral ratio of the Woranso-Mille specimen (Haile Selassie et al., 2010; Haile Selassie and Su, 2016) as a reference, whilst the missing diaphyseal material was not reconstructed, as this has no bearing upon the convex hull volume. The fibula was reconstructed by scanning a physical sculpt constructed by ATC, incorporating the cast of the well preserved distal portion of the fibula (A.L. 288-1at), proportioned to match our estimated tibial length and articulating anatomically with the tibia proximally and the talus distally. In the foot, the A.L. 288-1 talus was used to scale a scan of a reconstruction of the $\mathrm{OH} 8$ right foot in which missing components (principally the phalanges) were sculpted by ATC to the proportions of a modern human foot. The lengths of all reconstructed limb bones are presented in Table 5.

Upper limb The right scapula preserves the glenoid in its entirety and part of the spine and the base of the acromial process. The missing morphology was reconstructed through a thin plate spline morph of the modern human reference sample (SOM Table S1) through

431 geometric morphometric analysis of 20 type I and II landmarks and 20 curve semilandmarks. 
432 All landmark data are available as supplementary data on Figshare (DOI:

$43310.6084 / \mathrm{m} 9$.figshare.c.3462618), as is our reconstructed scapula model. The resulting

434 morphed model was then mirrored to produce a left scapula. A scan of the complete $A$.

435 sediba right clavicle (UW88-38) (http://www.morphosource.org) was scaled on the basis of a

436 fragment from A.L. 288-1 and also mirrored. The right humerus was based on the recent

437 reconstruction of Kappelman et al. (2016) and mirrored in place of the left.

438 A.L. 288-1 has well preserved left and right side proximal and distal ulnae (Johanson

439 et al., 1982) but on both sides regions of the midshaft are missing, necessitating estimation

440 of maximum length and longitudinal curvature. We reconstructed the missing parts of the

441 shaft in modeling clay after arranging the preserved parts in approximate anatomical

442 alignment, utilizing the ulnar maximum length estimation (from proximal to distal extremities

443 excluding the styloid process) of $220 \mathrm{~mm}$ (Kimbel et al., 1994) and longitudinal curvature of

$4442 \mathrm{~mm}$ (left) and $4 \mathrm{~mm}$ (right) in accordance with the estimates of Drapeau et al. (2005:Table

$4454)$.

446 The proximal, midshaft, and distal fragments of the right radius were aligned and

447 spaced using the proximal and distal articulations between the radius and the reconstructed

448 right ulna as a guide. The resulting maximum length of $204 \mathrm{~mm}$ is almost identical to the

449 value of $203 \mathrm{~mm}$ (95\% confidence interval [C.I.] $\pm 29 \mathrm{~mm}$ ) published by Asfaw et al. (1999).

450 As with the ulna, we have reconstructed the radius with slight longitudinal curvature.

451 Only the left capitate (A.L. 288-1w) and an unsided non-pollical proximal phalanx

452 (A.L. 288-1x) are preserved from the A.L. 288-1 hand. The dimensions of the capitate and of 453 the distal articular surface of the radius in A.L. 288-1, together with the metacarpal/ulna 454 length ratio and the metacarpal/phalangeal length ratios in other $A$. afarensis material (Bush 455 et al., 1982; Alba et al., 2003; Drapeau et al., 2005), place some constraints on the size and 456 shape of the hand in A.L. 288-1. A human hand obtained from the NCIA sample was scaled 457 to fit the A.L. $288-1$ w capitate and our estimates of second and third metacarpal lengths. 
Vertebral column The specimens A.L. 288-1 ae, A.L. 288-1 af, A.L. 288-1ad, A.L. 288-1ac,

460 and A.L. 288-1aa were originally interpreted as the bodies of a probable T6, a probable T8, 461 and T10, T11, and L3 vertebrae, respectively (Johanson et al., 1982). However, a recent revision by Meyer et al. (2015) interpreted these vertebrae as T6, T7, T9, T10, and L3, and we follow this numbering here. The number of lumbar vertebrae originally present in A.L. 288-1 has also been debated. Cook et al. (1983) suggested A.L. 288-1 had five lumbar vertebrae, yet Latimer and Ward (1993) observed six lumbar vertebrae in available skeletons of $A$. africanus (see also Robinson, 1972; Sanders, 1998) and argued this number is therefore likely to represent the primitive condition in hominins. They suggest the T13 of hominoids underwent transformation into L1 in hominins as a means of facilitating lumbar lordosis, resulting in Pliocene hominins possessing 12 thoracic and six lumbar vertebrae, and a subsequent reduction to the five lumbar vertebrae typical of Pleistocene and Holocene humans. Subsequent research (Williams et al., 2015, 2016) has argued that this is not correct and that australopiths had five lumbar vertebrae. We concur with this argument and in our reconstruction, A.L. 288-1 has five lumbar vertebrae. dimensions taken from vertebral columns from $H$. sapiens (a medieval sample and Andaman Islanders), P. troglodytes, and archaic hominins prior to around $1.5 \mathrm{Ma}$. It can be seen that the ratios of the heights of the surviving thoracic and lumbar vertebrae in AL288-1 are very similar to modern humans, particularly our smaller bodied Andaman sample, but are less similar to $P$. troglodytes. It is also very similar to that of STS-14. presented, depending upon the modern reference sample used (Table 7). We prefer the value based mainly on Andaman Islanders for the above reason and, as the maximum length, will reflect an upper limit for total body size. The dry column height for our reconstruction is $339.8 \mathrm{~mm}$, without accounting for intervertebral disc heights. Further adjustment to account for disc spacing based upon Gilad and Nissan (1986) and Kunkel et 
487 Cetumixab0522c0433 was manually segmented in Avizo, and the resulting PLY file was

488 scaled to match this height and to the width of the L3 from A.L. 288-1.

490 Thorax The subject of the shape of the Australopithecus thorax has been one of

491 considerable debate (Schmidt, 1983; Lewin and Foley, 2004; Haile Selassie et al., 2010;

492 Schmid et al., 2013; Latimer et al., 2016; ). Both a human 'barrel shape' and hominoid

493 'funnel shape' ribcage have been proposed for $A$. afarensis, with previous reconstructions

494 being based on very limited fragmentary remains. However, the recent find and subsequent

495 analysis of the Woranso-Mille thoracic remains have supported the $A$. afarensis thorax as

496 being a different form to either of these extremes, with a 'bell shaped' thorax being favored

497 (Latimer et al., 2016). As such, we reconstruct the A.L. 288-1 ribcage using an iterative,

498 geometric morphometric technique based upon a sample of both $H$. sapiens and $P$.

499 troglodytes.

500 The rib fragments of A.L. 288-1 were positioned using a reference thorax of a

501 modern human scaled to the height obtained above as a guide, purely as a guide for the

502 initial reconstruction. Where appropriate, fossil rib fragments were mirrored to create a

503 starting model based solely on A.L. 288-1 material. The right hand side was preferred as this

504 is generally the better preserved side. Medical CT scans of 10 modern human females were

505 subsequently sourced from the NCIA and 10 P. troglodyes from the Arizona Primate

506 Foundation collection (Available from http://www.carta.anthropogeny.org; SOM Table S1).

507 3D models of the ribcage (or individual ribs in the case of Pan) were extracted using the

508 freeware program Stradwin (Treece et al., 1999). For each rib of the modern ribcage

509 dataset, four sets of 61 semilandmarks were placed on the anterior, posterior, cranial, and

510 caudal extremities of the rib head (with up to four fixed landmarks to mark the position of the

511 tubercle and up to four at the head). The semilandmarks were then resampled equidistantly

512 using the R package Morpho (Schlager 2013). Sixty-one semilandmarks were chosen,

513 rather than 15 as employed by Garcia Martinez et al. (2014) in the Kebara reconstruction, as

514 A.L. 288-1's ribs are much more fragmentary. A greater number of landmarks therefore 
515 allows for more of the original fossil data to influence the resulting reconstruction.

516 Semilandmarks missing from each of the A.L. 288-1 ribs were then reconstructed using thin

517 plate splines based upon the entire modern hominoid (i.e., both $H$. sapiens and $P$.

518 troglodytes) reference dataset, in the R package Morpho. Final reconstructed polygon

519 models were created by morphing a chimpanzee rib onto the configuration of predicted

520 landmarks for AL288-1 using the 'warprefmesh' function in Geomorph (version 3.0.3; Adams

521 et al., 2013). Each rib reconstruction was also 3D printed to check its feasibility. The

522 simplified rib heads presented here act only to articulate with the reference spine, and with

523 the exceptions of ribs 7 and 11 , have limited biological significance beyond a prediction of

524 overall size. The resulting 3D models were subsequently rearticulated onto the base spine

525 skeletal model. The complete right hand side of the rib cage was mirror-imaged to give the

526 left portion. All landmark data are available as supplementary data on Figshare (DOI:

$527 \quad 10.6084 / \mathrm{m9}$. figshare.c.3462618)

528 Given the fragmentary state of the thorax, ribs 2 and 12 were not included as they

529 are entirely absent from the original. Rib 11 was also not reconstructed in its entirety, as it is

530 extremely variable in length both within and between species (T.O'M., pers obs.), and its

531 curvature does not affect the reconstructed convex hull. As previously stated, a benefit of

532 convex hulling is that the hulls effectively 'snap-to' the outermost points of the region and are

533 therefore insensitive to any missing material within the bounds of the extremities.

534 Furthermore, our attempt to morph a ribcage on the basis of limited thoracic material

535 represents an improvement over previous paleontological reconstructions in which an

536 articulated modern ribcage is simply scaled and substituted into the fossil (Basu et al.,

537 2016). Finally, a modern human sternum from the NCIA sample was scaled to approximately

$53860 \%$ in all directions and articulated with the thorax.

540 Cranium For the cranium, a scan of the composite $A$. afarensis A.L. 333 reconstruction

541 (available on http://www.morphosource.org) was scaled to fit the existing mandible and

542 cranial vault fragments of A.L. 288-1. 
544 The overall height of A.L. 288-1 is reconstructed as $1106 \mathrm{~mm}$, and bi-iliac breadth is 264

$545 \mathrm{~mm}$. The whole model accompanies the publication as supplementary data on Figshare

546 (DOI: 10.6084/m9.figshare.c.3462618; with the exception of the proximal tibia, reconstructed

547 humerus, and distal femur, which can be obtained from http://www.elucy.org and the

548 clavicle, which can be obtained from http://www.morphosource.org). All landmark datasets

549 used in the model construction are also available, as well as landmarks indicating placement

550 of model files available from elsewhere (SOM Figure S2a,b).

552 Sensitivity analysis In volumetric reconstructions, the majority of total volume lies within the trunk. As such, convex hull mass estimates are particularly sensitive to uncertainty in the articulation of this region. As stated above, the height of the model presented here is in broad agreement with previous reconstructions, and we can be relatively confident in the dimensions of the trunk in the superior-inferior direction. However, to quantify the effect of uncertainty in the remaining two dimensions, two additional models were created in which the entire trunk segment (pelvis, ribs, vertebrate, scapula, sternum, and clavicle) were scaled in the dorsoventral and mediolateral directions by $10 \%$ and $20 \%$, respectively.

Results

Predictive model

The results of the regression analyses can be seen in Table 8 and Figure 6A. The

564 OLS fit is characterized by a high correlation coefficient $\left(r^{2}=0.988\right)$ and a \%SEE of $20 \%$,

565 whilst the type-II RMA regression has a \%SEE of $14 \%$. When phylogenetic non-

566 independence was taken into account by conducting PGLS, \%SEE increased to $26 \%$.

567 Ordinary least squares is typically the preferred regression type when used in a predictive

568 capacity (Smith, 1994; 2009) and is therefore reported throughout. Application of RMA

569 results in very similar predictions (within $\sim 2 \%$ ) to those generated using OLS. 

cadaver and values were therefore assigned using a pre-existing bivariate equation based upon radial head surface area in extant Hominoids (Ruff, 2003). As such, these values are estimates themselves with associated errors. Regression analyses were therefore rerun excluding these individuals and the results presented in SOM Table S2. Exclusion of these individuals had a negligible effect on the predictive equation, however, and resulting mass estimates deviated by $\sim 5 \%$ from the original equation. Likewise, some individuals sourced from the National Museum of Scotland had been subject to postmortems and removal of an unqualifiable mass of gut content. Removal of these individuals also had a very minor impact on the predictive equation (SOM Table S3) and decreased fossil mass estimates by $\sim 2 \%$ relative to the original equation.

\section{Application to modern individuals of known body mass}

Overall, the original OLS predictive model performed well when applied to modern primate specimens of known body mass. The model performed best when predicting the mass of a male human of normal BMI (21.4), reliably estimating body mass to within $800 \mathrm{~g}$ (Table 9). For the night monkey and squirrel monkeys, percentage error on the mass estimates were within the bounds of what would be expected on the basis of a mean absolute prediction error of $13.5 \%$ calculated for the OLS predictive equation. However, in the case of the Japanese macaques, prediction error was high (27-29\%, Table 9). The

590 "leave-one-out" jackknife analysis resulted in an average prediction error of $14.8 \%$, ranging 591 from $0.5-37.4 \%$.

592 The predictive equation performed as expected when applied to a sample of human males with varying body mass index (BMI, Fig. 7). Individuals with a BMI falling within the 'healthy' range (18.5-25) had percentage prediction errors between 1-15\%, in line with the

595 jackknife analysis above. In individuals characterized as overweight (BMI 25-30) or obese

$596(\mathrm{BMI}>30)$, predicted mass increasingly deviated from known mass, resulting in a prediction 597 error of $32 \%$ in one particularly obese individual. 
Application to A.L. 288-1

600

Total height of the A.L. 288-1 reconstruction presented here is $1106 \mathrm{~mm}$, which is

601 slightly taller than the widely accepted estimate of $1070 \mathrm{~mm}$ by Jungers (1988a). Likewise, reconstructed bi-iliac breadth is $264 \mathrm{~mm}$, which is at the upper end of the range of published estimates of 228-268 mm (Berge and Goularas, 2010; Ruff, 2010). In contrast, bi-iliac breadth of the $10 \%$ and $20 \%$ expanded models is $290 \mathrm{~mm}$ and $317 \mathrm{~mm}$, respectively, which are well above previously published estimates.

Fitting convex hulls around the body segments of our 3D reconstruction of $A$. afarensis (288-1) resulted in a total convex hull volume of $0.0148 \mathrm{~m}^{3}$ (Fig. 8, Table 10). Increasing the dorsoventral and mediolateral dimensions of the trunk segment by $10 \%$ and $20 \%$ produced total convex hull volumes of $0.0170 \mathrm{~m}^{3}$ and $0.0195 \mathrm{~m}^{3}$, respectively. When convex hull volume was substituted into the OLS predictive equation (Table 8), the body mass of $A$. afarensis was estimated as $20.4 \mathrm{~kg}$ (95\% prediction interval: $13.5-30.9 \mathrm{~kg})$. Models expanded by $10 \%$ and $20 \%$ in the trunk region resulted in mass estimates of $23.5 \mathrm{~kg}$ (95\% predictive interval: $15.5-35.8 \mathrm{~kg})$ and $27.0 \mathrm{~kg}$ (95\% prediction interval: $17.7-41.0 \mathrm{~kg})$, respectively. Segment inertial properties are not estimated in the present study, but will be incorporated into future multibody dynamic analyses of locomotion.

616

\section{Discussion}

618 The volumetric model of $A$. afarensis (A.L. 288-1) presented here results in an average body

619 mass estimate of $20.4 \mathrm{~kg}$. This figure is lower than several mass estimates published

620 elsewhere for this specimen (Fig. 3), although the sizeable 95\% prediction intervals overlap many previous studies and suggest a mass up to $31 \mathrm{~kg}$ is statistically supported. When compared with previous studies, the lower average mass estimate calculated here may be

623 consistent with three alternative explanations: (1) that the convex hull predictive model does

624 not work when applied to A. afarensis, (2) that the articulated model of A.L. 288-1 is 
625 incorrect, or (3) that the body mass of A.L. 288-1 may have been lower than previously

626 estimated, which are discussed in turn below.

627

628 The convex hull predictive model does not work when applied to A. afarensis

629 Here we have shown that the convex hull mass prediction model performs reasonably well

630 when applied to several modern primate individuals (Table 9), including humans, squirrel

631 monkeys, and a species of night monkey not included in the original training dataset. The

632 convex hulling technique defines a predictable relationship between the overall volume of

633 the skeleton and the amount of soft tissue held beyond its bounds. For convex hulling to

634 underestimate mass therefore, A.L. 288-1 would be required to have held far more soft

635 tissue outside the extent of the convex hull than would characterize a modern primate of

636 similar size.

637 Many of the modern primate carcasses digitized for the present study were captive

638 individuals rather than wild-caught specimens. The results of Leigh (1994) for anthropoid

639 primates suggest captive body weight is on average $27 \%$ higher than non-captive weight.

640 However, captive African apes were not found to be significantly heavier than wild

641 individuals. As these species (alongside humans) are the most relevant taxa for assessing

642 A.L. 288-1, this suggests the use of zoo individuals might not be a factor in the low predicted

643 masses of A.L. 288-1. In contrast, Leigh (1994) also found macaques to be particularly

644 susceptible to obesity, with captive body mass on average $58 \%$ above species averages for

645 wild mass. This may go some way to explaining the poor performance of our predictive

646 equation, considerably underestimating the body mass of the captive specimens of Macaca

647 fuscata (Table 9). This issue is also highlighted in Figure 7, in which the predictive

648 performance of the convex hull equation is related to the BMI of male humans, with

649 percentage error increasing as a function of BMI. This is unsurprising given the nature of the

650 convex hulling approach, as one assumes a consistent 'primate-average' amount of soft

651 tissue to be distributed outside the bounds of the skeleton, and does not account for extreme

652 volumes of adipose tissue. Whilst it is reassuring that humans with a 'normal' BMI fall within 
653 the range of predictive error expected of the equation, these data are illuminating with

654 regards to the sensitivity of the approach to assumed body composition. Although perhaps

655 less of a problem for primates, this would be an issue for taxa known to undergo considerable seasonal shifts in body composition, such as migratory species.

As a 'wild' individual, there is little reason to believe A.L. 288-1 carried unusually large stores of fat above and beyond modern captive primates. Likewise, there is no evidence for $A$. afarensis possessing considerably more muscle beyond the bounds of the skeleton compared to similar sized modern primates, such as the olive baboon (Papio anubis) included in the training dataset, and muscle attachment sites on the A.L. 288-1 skeleton are of comparable prominence to those of other large bodied primates. We therefore consider it unlikely that the low mass estimate presented here is attributable to additional soft tissues that have been unaccounted for in the original convex hull model. cadaveric specimens. Whilst the sensitivity analysis conducted above has suggested the inclusion of individuals who have undergone a postmortem does not considerably impact upon estimated masses for A.L. 288-1, it is still the case that our predictive model has not been tested on live non-human primates. Although the equation performs as expected on live humans of normal BMI, further veterinary CT data on non-cadaveric primates would be a welcome future addition. Furthermore, the NCIA human dataset is limited to male patients.

672 Additional whole-body CT data of female subjects may be illuminating with regards to the 673 potential effect of sexual dimorphism on predictive performance.

This is almost certainly the case to some extent. Less than half of the skeleton is preserved, and what remains has been subject to taphonomic deformation. A substantial amount of 'sculpting' has been necessary in order to create an articulated model upon which convex hulling can operate. Whilst considerable effort has been made to ensure the

680 reconstruction of damaged/missing elements incorporates the maximum amount of 
681 information from existing fragments and is grounded within the context of other closely

682 related taxa, including modern humans, some error is inevitable. Furthermore, due to the

683 volumetric nature of the mass estimate, any errors associated with reconstructing the linear

684 dimensions of missing/damaged skeletal elements become proportionally larger when

685 incorporated into the final volumetric model. Unfortunately, as with any paleontological

686 reconstruction, the degree to which this model accurately reflects the body shape of A.L.

687 288-1 will never be known, though the reconstruction may be corroborated through further

688 finds of fossil skeletons. The more pertinent question then becomes the sensitivity of the

689 convex hulling approach to potential inaccuracies.

690 Here the 'trunk' segment comprises $71 \%$ of total convex hull volume of A.L. 288-1,

691 and errors in this region of the body can impact significantly on final body mass estimates.

692 Not only does the 'trunk' consist of many skeletal elements of uncertain articulation

693 (including the pelvis, ribs, and scapulae), the morphology of said elements is frequently

694 contested in the literature, (e.g., Aiello and Dean, 1999). In addition, the trunk region is also

695 one of the poorest in terms of fossil preservation, with ribs being particularly fragile and

696 subject to loss. For this reason, we focused our sensitivity analysis on the effect of overall

697 trunk shape on resulting mass estimates.

698 A height of $1106 \mathrm{~mm}$ for A.L. 288-1 agrees with previous estimates of stature

699 (Jungers, 1988a), and the bi-iliac breadth of our 'best-guess' reconstruction overlaps with

700 those published elsewhere (Berge and Goularas, 2010; Ruff, 2010), with both erring on the

701 upper end of previous studies. Yet combined they result in a convex hull mass estimate

702 falling below the majority of other studies (Fig. 3) at $20.4 \mathrm{~kg}$. In contrast, to achieve a mean

703 body mass estimate in excess of $25 \mathrm{~kg}$ that is more convergent with previous studies

704 requires the trunk region to be expanded by $\sim 20 \%$, resulting in a bi-iliac breadth of $317 \mathrm{~mm}$,

705 far above the range of values previously considered feasible. In addition, the overall body

706 shape necessary to achieve such high values of body mass appears disproportionally broad

707 in the shoulder and thoracic region (Fig. 9). 
Alternative metrics for quantifying 'external body size' including 'stature' (Porter, 1995) or 'stature x body breadth' (Ruff, 1994, 2002) have previously been used to estimate

710 hominin body mass. Such studies have been criticized, however, for involving an additional

711 stage of prediction (estimating stature from preserved long bone lengths and subsequently estimating body mass from stature) and for requiring a considerable portion of the skeleton to be recovered. We must therefore recognize that the convex hulling technique presented

714 here is even more limited in this sense, requiring an entire 3D articulated skeleton to operate on and a non-trivial degree of digital restoration to achieve the model. However, the application of sensitivity analyses in the form conducted above does permit a visual check on body size reconstructions, allowing for the results of linear predictive models (X species weighed $\mathrm{Y} \mathrm{kg}$ ) to be placed into the context of what this means for the body shape of the taxa in question. In this instance, we consider the $20 \%$ expanded trunk model to be implausible in the context of hominin body shape, as it would imply that all of the thoracic remains from A.L. 288-1 are taphonomically distorted and result in an even smaller rib cage than in life. This is not particularly feasible given the evidence from KSD-VP-1/1, which suggests a thorax morphology more like the condition found in modern humans. This, however, assumes that the scaling has no effect on thoracic form, and this is an area in which more research needs to be done, for example, through analysis of small bodied modern human populations such as the Andaman Islanders or Khoi-San.

The body mass of A.L. 288-1 may have been lower than previously estimated

As far as the authors are aware, this is the first attempt to estimate the body mass of

730 a fossil hominin using a 3D volumetric technique. That the results presented here for the mass of $A$. afarensis differ quite markedly from those published previously is perhaps unsurprising. Within the wider discipline of paleontology, volumetric reconstructions of fossil birds (Brassey et al., 2013, 2016) and dinosaurs (Henderson, 2006; Sellers et al., 2012) have produced mass estimates lower than traditionally put forward using straightforward linear skeletal dimensions. Interestingly, the study of Porter (1995) perhaps comes closest to 
ours in terms of methodology, in which the BMI of A.L. 288-1 was predicted and body mass

737 back-calculated by substituting in a stature of $1050 \mathrm{~mm}$. Porter (1995) estimated a probable

738 mass of $25 \mathrm{~kg}$, and suggested that the values of $28 \mathrm{~kg}$ and greater, favored elsewhere, were

739 improbable without the specimen having an extremely high BMI.

$740 \quad$ Most existing mass estimates of A.L. 288-1 rely upon limb material and produce

741 estimates typically spanning 25-37 kg (Fig. 3). If the low estimates for body mass calculated

742 here are reliable, this would suggest the limb bones of $A$. afarensis were comparatively

743 overbuilt relative to modern humans and apes. Recent evidence has suggested that A.L.

744 288-1 had relatively more robust limb bone diaphyses compared to articular size (Ruff et al.,

745 2016). Yet the extent to which this translates into the specimen possessing a robust

746 appendicular skeleton relative to total body size can only be understood in the light of non-

747 limb based reconstructions as presented here. Future research may incorporate the results

748 of volumetric mass estimates into further biomechanical analyses of skeletal loading to

749 determine the relative robustness of the skeleton during locomotion.

750

\section{Conclusions}

752 The method presented here suggests that based on a complete reconstruction of the skeleton, we should expect the body mass of A.L. $288-1$ to be $20.4 \mathrm{~kg}$. This is considerably lower than predicted by most published sources although still within the previously published range. This reduction is very much in line with the reductions in body mass estimates seen in other paleontological studies when volumetric approaches are used and may well reflect the fact that A.L. $288-1$ is a considerably lighter hominin than has previously been thought. However, it must be remembered that volumetric body masses are particularly sensitive to the reconstruction of the trunk, and the incomplete nature of the preserved ribcage may be the source of this discrepancy in mass estimates. Even so, we would suggest that the

761 heaviest of the previous estimates would require a degree of thorax expansions that would seem unlikely. Of course, this can only be tested when more complete fossils are available. 
Whilst convex hulling is a very novel volumetric approach to estimating the mass of

764 A.L. 288-1, there are obvious drawbacks. Not only is the application of convex hulling limited

765 to relatively complete skeletons, but it also requires a modern reference dataset of whole

766 body CT scans, preferably of individuals of known body mass. There are several potential

767 candidates for the future application of volumetric mass estimation to fossil hominin and

768 primate material, however. The Regourdou Neanderthal has a considerable proportion of

769 thoracic material preserved, whilst the Homo erectus (WT15000) 'Turkana Boy' is

770 exceptionally complete (albeit immature, thus requiring an ontogenetic reference dataset).

771 Once fully described, the Australopithecus 'Little Foot' (Stw 573) may be viable, as will

772 Homo naledi (this would currently require a composite, although more complete individuals

773 may be discovered in the future). Oreopithecus bambolii (IGF 11778) would require

774 digitization and retrodeformation, but is fairly well represented, likewise Ardipithecus ramidus

775 (ARA-VP-6/500), if and when the material becomes publicly available.

776 Whilst potentially a limiting factor in the past, access to CT facilities is becoming

777 cheaper and more straightforward, and collecting large modern comparative datasets is now

778 entirely feasible. Accessing appropriate cadaveric primate material can indeed be

779 problematic. Yet assuming, as a field, we hold ourselves to the minimum standards and

780 additional best-practices put forward by Davies et al. (2017), the sharing of CT and 3D

781 surface model datasets via online repositories should ensure an ever increasing pool of data

782 to draw from.

783 Therefore, even in the light of the above limitations, we remain optimistic that volumetric

784 mass estimation has a future role to play in the field of human evolution, most obviously

785 through integration with biomechanical studies of locomotion. And although unlikely to

786 replace traditional linear allometric methods, convex hulling ought to complement such

787 studies wherever possible, as a means of validating the feasibility of mass estimates derived

788 by other approaches. Volumetric reconstructions will also prove particularly useful in

789 exploring the impact of changes in bodily dimensions (pelvis width, ribcage shape) on mass 
sets across evolutionary lineages. In particular, future work should explore the possible

791 effects of ontogeny and sexual dimorphism on volumetric body mass estimates.

\section{Acknowledgments}

We would like to thank the editor, guest editor, and two anonymous reviewers for

795 their suggested improvements to the manuscript. The authors would like to acknowledge the

796 Kyoto Primate Research Institute (KUPRI), the Visible Human Project, the Cancer Imaging

797 Archive; CARTA, and Morphosource.org for access to datasets. We also thank Doug Boyer

798 (Duke University) for making scans of the A.L. 333 composite skull, and AL288-1 pelvis and

799 sacrum available to us. We acknowledge Andrew Kitchener (National Museum of Scotland,

800 Edinburgh) for providing primate specimens and Martin Baker (University of Liverpool) for

801 conducting CT scanning. We thank Diana Mahoney-Swales for logistical help with arranging

802 the scanning of casts, and Robert Brocklehurst (University of Manchester) for assistance

803 with data management. We also thank C. Owen Lovejoy (Kent State University) for providing

804 a reference model of the A.L. 288-1 pelvis used during preliminary stages and Martin

805 Hauesler for access to his reconstruction of the AL288-1 pelvis. We thank Stephanie Davy-

806 Jow for assistance with some of the preliminary reconstruction, particularly the vertebral

807 column. Data for the vertebral reconstruction were courtesy of Juho Antii-Junno (University

808 of Oulu). Data from Andaman Islanders was collected by T.O'M. with the permission of

809 Robert Kruszynski, Natural History Museum London. Aspects of this work were funded by

810 the Natural Environment Research Council (NE/C520447/1, NE/C520463/1 and

$811 \mathrm{NE} / \mathrm{J} 012556 / 1)$. 
813 Adams, D.C., Otarola-Castillo, E., 2013. Geomorph: an R package for the collection and analysis of geometric morphometric shape data. M. Ecol. Evol. 4, 393-399.

Aiello, L.C., Dean, M.C. 1999. An introduction to human evolutionary anatomy. Academic Press, London.

Aiello, L.C., Wood, B.A., 1994. Cranial variables as predictors of hominine body mass. Am. J. Phys. Anthropol. 95, 409-426.

Alba, D.M., Moyà-Solà, S., Kohler, M., 2003. Morphological affinities of the Australopithecus afarensis hand on the basis of manual proportions and relative thumb length. J. Hum. Evol. 44, 225-254.

Alexander, R.M.N., 1985. Mechanics of posture and gait of some large dinosaurs. Zool. J. Linn. Soc. 83, 1-25.

Arnold, C., Matthews, L.J., Nunn, C.L., 2010. The 10kTrees website: a new online resource for primate phylogeny. Evol. Anthropol. 19, 114-118.

Asfaw, B., White, T., Lovejoy, O., Latimer, B., Simpson, S., Suwa, G., 1999. Australopithecus garhi: a new species of early hominid from Ethiopia. Science 284, $629-635$.

Auerbach, B.M., Ruff, C.B., 2004. Human body mass estimation: a comparison of "morphometric" and "mechanical" methods. Am. J. Phys. Anthropol. 125, 331-342.

Barber, C.B., Dobkin, D.P., Huhdanpaa, H., 1996. The quickhull algorithm for convex hulls. ACM T. Math. Software 22, 469-483.

833 Basu, C., Falkingham, P.L., Hutchinson, J.R., 2016. The extinct, giant giraffid Sivatherium giganteum: skeletal reconstruction and body mass estimation. Biol. Lett. 12, 20150940.

Bates, K.T., Manning, P.L., Hodgetts, D., Sellers, W.I., 2009. Estimating mass properties of dinosaurs using laser imaging and 3D computer modelling. PLoS One 4, e4532. a giant: re-evaluating Dreadnoughtus body mass. Biol. Lett. 11, 20150215. 
840 Berge, C., Goularas, D., 2010. A new reconstruction of Sts 14 Pelvis (Australopithecus africanus) from computed tomography and three-dimensional modeling techniques.

Berger, L.R., de Ruiter, D.J., Churchill, S.E., Schmid, P., Carlson, K.J., Dirks, P.H.G.M., Kibii, J.M., 2010. Australopithecus sediba: A New Species of Homo-Like Australopith from South Africa. Science 328, 195-204.

Braddy, S.J., Poschmann, M., Tetlie, O.E., 2008. Giant claw reveals the largest ever arthropod. Biol. Lett. 4, 106-109.

Brassey, C.A., 2017. Body mass estimation in paleontology: A review of volumetric techniques. Paleontol. Soc. Pap. 22, 133-156.

Brassey, C. A., Sellers, W. I., 2014. Scaling of convex hull volume to body mass in modern primates, non-primate mammals and birds. PLoS One 9, e91691.

Brassey, C.A., Holdaway, R.N., Packham, A.G., Anne, J., Manning, P.L., Sellers, W.I., 2013. More than one way of being a Moa: Differences in leg bone robustness map divergent evolutionary trajectories in Dinornithidae and Emeidae (Dinornithiformes). PLoS One 8, e82668.

Brassey, C.A., O’Mahoney, T.G., Kitchener, A.C., Manning, P.L., Sellers, W.I., 2016. Convex-hull mass estimates of the dodo (Raphus cucullatus): application of a CTbased mass estimation technique. PeerJ 4, e1432.

Bräuer, G., 1988. Osteometrie. In Knußmen, R. (Ed.) Anthropologie: Handbuch der vergleichenden Biologie des Menschen, Volume 1. Gustav Fischer Verlag, Stuttgart. Brown, P., Sutikna, T., Morwood, M.J., Soejono, R.P., Jatmiko, Wayhu Saptomo, E., Awe Due, R., 2004. A new small-bodied hominin from the Late Pleistocene of Flores, Indonesia. Nature 431, 1055-1061.

Bush, M.E., Lovejoy, C.O., Johanson, D.C., Coppens, Y., 1982. Hominid carpal, metacarpal, and phalangeal bones recovered from the Hadar Formation: 1974-1977 
collections. Am. J. Phys. Anthropol. 57, 651-677.

Cheein, F.A., Guivant, J., 2014. SLAM-based incremental convex hull processing approach for treetop volume estimation. Comput. Electron. Agr. 102, 19-30.

Clark, K., Vendt, B., Smith, K., Freymann, J., Kirby, J., Koppel, P., Moore S., Phillips, S., Maffitt, D., Pringle, M., Tarbox, L., Prior, F., 2013. The Cancer Imaging Archive (TCIA): maintaining and operating a public information repository. J. Digit. Imaging 26, 1045-1057.

Clarke, R.J., 1998. First ever discovery of a well-preserved skull and associated skeleton of an Australopithecus. S. Afr. J. Sci. 94, 460-463.

Colbert, E.H., 1962. The weights of dinosaurs. Am. Mus. Novitates 2076, 1-16.

Conroy, G.C., 1987. Problems of body-weight estimation in fossil primates. Intl. J. Primatol. 8, 115-137.

Cook, D.C., Buikstra, J.E., DeRousseau, C., Johanson, D.C., 1983. Vertebral pathology in the Afar australopithecines. Am J. Phys. Anthropol. 60, 83-102.

Crompton, R.H., Weijie, L.Y.W., Günther, M., Savage, R., 1998. The mechanical effectiveness of erect and "bent-hip, bent-knee" bipedal walking in Australopithecus afarensis. J. Hum. Evol. 35, 55-74.

Davies, T.G., Rahman, I.A., Lautenschlager, S., Cunningham, J.A., Asher, R.A., Barrett, P.M., Bates, K.T., Bengtson, S., Benson, R.B.J., Boyer, D.M. et al. 2017. Open data and digital morphology. Proc. R. Soc. B. 284, 20170194.

Dingwall, H.L., Hatala, K.G., Wunderlich, R.E., Richmond, B.G., 2013. Hominin stature, body mass, and walking speed estimates based on 1.5 million-year-old fossil footprints at Ileret, Kenya. J. Human Evol. 64, 556-568.

Drapeau, M.S.M., Ward, C.V., Kimbel, W.H., Johanson, D.C., Rak, Y., 2005. Associated cranial and forelimb remains attributed to Australopithecus afarensis from Hadar, Ethiopia. J. Human Evol. 48, 593-642. 
892 Fariña, R.A., Vizcaíno, S.F., Bargo, M.S., 1998. Body mass estimations in Lujanian (late Pleistocene-early Holocene of South America) mammal megafauna. Mastozool. Neotrop. 5, 87-108.

Fleagle, J.G., 2013. Primate adaption and evolution. Academic Press, San Diego, p. 464.

Franciscus, R.G., Holliday, T.W., 1992. Hindlimb skeletal allometry in plio-pleistocene hominids with special reference to AL-288-1 (" Lucy"). B. Mém. Soc. Anthropol. Paris. $4,5-20$.

Garcia-Martinez, D., Barach, A., Recheis, W., Utrilla, C., Torres Sanchez, I., Garcia Rio, R., Bastir, M., 2014. On the chest size of Kebara 2. J. Hum. Evol. 7, 69-72.

Gilad, I. and Nissan, M., 1986. A Study of Vertebra and Disc Geometric Relations of the Human Cervical and Lumbar Spine. Spine 11(2), 154-157

903

Grabowski, M., Hatala, K.G., Jungers, W.L., Richmond, B.G., 2015. Body mass estimates of hominin fossils and the evolution of human body size. J. Human Evol. 85, 75-93.

Gregory, W., 1905. The weight of the Brontosaurus. Science 22, 572.

Gunga, H., Kirsch, K., Baartz, F., Röcker, L., Heinrich, W., Lisowski, W., Wiedemann, A., Albertz, J., 1995. New data on the dimensions of Brachiosaurus brancai and their physiological implications. Naturwissenschaften 82, 190-192.

Gunga, H., Kirsch, K., Rittweger, J., Röcker, L., Clarke, A., Albertz, J., Wiedemann, A., Mokry, S., Suthau, T., Wehr, A., Heinrich, W-D., Shultze, H.P., 1999. Body size and body volume distribution in two sauropods from the Upper Jurassic of Tendaguru

913 Gunz, P., Mitteroecker, P., Neubauer, S., Weber, G.W., and Bookstein, F.L., 2009.

914 Principles for the virtual reconstruction of hominin crania. J. Hum. Evol. 57, 48-62.

915 Haile-Selassie, Y., Su, D.G. (Eds.), 2016. The Postcranial Anatomy of Australopithecus

916 afarensis New Insights from KSD-VP-1/1. Springer, Drotrecht.

917 Haile Selassie, Y., Latimer, B.M., Alene, M., Deino, A.L., Gilber, L., Melillo, S.M., Saylor, 918 B.Z., Scott, G.R., and Lovejoy, C.O., 2010a. An early Australopithecus afarensis 919 postcranium from Woranso-Mille, Ethiopia. PNAS 107, 12121-12126. 
920 Haile-Selassie, Y., Saylor, B., Deino, A., Alene, M., Latimer, B., 2010b. New hominid fossils

921 from Woranso-Mille (Central Afar, Ethiopia) and taxonomy of early Australopithecus.

$922 \quad$ Am. J. Phys. Anthropol. 141, 406-617.

923 Harris, S., Cresswell, W., Forde, P., Trewhella, W., Woollard, T., Wray, S., 1990.

$924 \quad$ Home-range analysis using radio-tracking data-a review of problems and techniques

925 particularly as applied to the study of mammals. Mamm. Rev. 20, 97-123.

926 Hartwig-Scherer, S., 1993. Body weight prediction in early fossil hominids: Towards a taxon-

927 "independent” approach. Am. J. Phys. Anthropol. 92, 17-36.

928 Hauesler, M., Martelli, S.A., Boeni, T., 2002. Vertebrae numbers of the early hominid lumbar spine. J. Hum. Evol. 43, 621-643

930 Henderson, D., 2006. Burly gaits: Centers of mass, stability, and the trackways of sauropod

931 dinosaurs. J. Vert. Paleo. 26, 907-921.

932 Hens, S.M., Konigsberg, L.W., Jungers, W.L., 2000. Estimating stature in fossil hominids:

933 which regression model and reference sample to use? J. Hum. Evol. 38, 767-784.

934 Herrero-Huerta, M., González-Aguilera, D., Rodriguez-Gonzalvez, P., Hernández-López, D.,

935 2015. Vineyard yield estimation by automatic 3D bunch modelling in field conditions.

$936 \quad$ Comput. Electron. Agr. 110, 17-26.

937 Herridge, V.L, Lister, A.M., 2012. Extreme insular dwarfism evolved in a mammoth. Proc. R.

$938 \quad$ Soc. B. 279, 3193-3200.

939 Holliday, T.W., Fransiscus, R.G., 2009. Body size and its consequences: Allometry and the

940 lower limb of Liang Bua 1 (Homo floresiensis). J. Hum. Evol. 57, 223-228.

941 Hutchinson, J.R., Ng-Thow-Hing, V., Anderson, F.C., 2007. A 3D interactive method for 942 estimating body segmental parameters in animals: application to the turning and 943 running performance of Tyrannosaurus rex. J. Theor. Biol. 246, 660-680. 
944 Hutchinson, J.R., Bates, K.T., Molnar, J., Allen, V., Makovicky, P.J., 2011. A computational analysis of limb and body dimensions in Tyrannosaurus rex with implications for locomotion, ontogeny, and growth. PLoS One 6, e26037.

948

Jiménez, P., Thomas, F., Torras, C., 2001. 3D collision detection: a survey. Comput. Graph. 25, 269-285.

Johanson, D., Edey, M.A., 1981. Lucy: The beginnings of humankind. Simon and Schuster, New York.

Johanson, D.C., Lovejoy, C.O., Kimbel, W.H., White, T.D., Ward, S.C., Bush, M.E., Latimer, B.M., Coppens, Y., 1982a. Morphology of the Pliocene partial hominid skeleton (A.L. 288-1) from the Hadar Formation, Ethiopia. Am. J. Phys. Anthropol. 57, 403-451.

Johanson, D.C., Taieb, M., Coppens, Y., (editors). 1982b. Special issue: Pliocene hominids from Hadar, Ethiopia. Am J. Phys. Anthropol. 57, 373-719.

Jungers, W.L., 1982. Lucy's limbs: skeletal allometry and locomotion in Australopithecus afarensis. Nature 297, 676-678.

Jungers, W.L., 1988a. Lucy's length: Stature reconstruction in Australopithecus afarensis (A.L. 288-1) with implications for other small-bodied hominids. Am. J. Phys. Anthropol. 76, 227-231

Jungers, W.L., 1988b. New estimates of body size in australopithecines. In: Grine, F.E. (Ed.), Evolutionary history of the "robust" australopithecines. Transaction Publishers, New Jersey, pp. 115-125.

Jungers, W.L., 1990. Problems and methods in reconstructing body size in fossil primates. Tuukkanen, J., 2009. Temporal trends in vertebral size and shape from Medieval to modern-day. PLoS One 4(3), e4836. doi:10.1371/journal.pone.0004836 
972 Kaiser, A., Klok, J., 2008. Do giant claws mean giant bodies? An alternative view on exaggerated scaling relationships. Biol. Lett. 4, 279-280.

974 Kappelman, J., 1996. The evolution of body mass and relative brain size in fossil hominids.

975 J. Hum. Evol. 30, 243-276.

976 Kappelman J., Ketcham, R.A., Pearce, S., Todd, L., Akins, W., Colbert, M.W., Feseha, M. Maisano, J.A., Witzel, A., 2016. Perimortem fractures in Lucy suggest mortality from fall out of tall tree. Nature 537, 503-507. doi:10.1038/nature19332.

Kibii, J.M., Churchill, S.E., Schmid, P., Carlson, K.J., Reed, N.D., de Ruiter, D.J., Berger,

Kimbel, W.H., Johanson, D.C., Rak, Y., 1994. The first skull and other new discoveries of 982

Australopithecus afarensis at Hadar, Ethiopia. Nature 368, 449-451.

Konigsberg, L.W., Hens, S.M., Jantz, L.M., Jungers, W.L., 1998. Stature estimation and calibration: Bayesian and maximum likelihood perspectives in physical anthropology. Am. J. Phys. Anthropol. 107, 65-92.

Kramer, P., 1999. Modelling the locomotor energetics of extinct hominids. J. Exp. Biol. 202, 2807-2818.

Kramer, P., Eck, G., 2000. Locomotor energetics and leg length in hominid bipedality. J. Hum. Evol. 38, 651-666.

Kunkel, M.A., Herkommer, M., Reinehr, M., Böckers, T.M., Wilke, H.J., 2011. Morphometric analysis of the relationships between intervertebral disc and vertebral body heights: An anatomical and radiographic study of the thoracic spine. J. Anat. 219, 375-387.

993 Latimer, B., Ward, C., 1993. The thoracic and lumbar vertebrae. In Walker, A.,

994 Leakey, R. (Eds.) The Nariokotome Homo erectus skeleton. Berlin, Springer, pp. 267-293.

995 Latimer, B.M., Lovejoy, C.O., Spurlock, L., Haile-Selassie, Y., 2016. The thoracic cage of 996 KSD-VP-1/1. In: Haile-Selassie, Y., Su, D.F. (Eds.) The Postcranial Anatomy of 

Australopithecus afarensis: New Insights from KSD-VP-1/1. Springer, New York, pp. $143-153$.

999 Lavin, S.R., Karasov, W.H., Ives, A.R., Middleton, K.M., Garland Jr, T., 2008. Morphometrics of the avian small intestine compared with that of nonflying mammals: a phylogenetic

1001 approach. Physiol. Biochem. Zool. 81, 526-550.

1002

Leigh, S.R., 1994. Relations between captive and noncaptive weights in anthropoid primates. Zoo Biol. 13, 21-43.

Leutenegger, W., 1987. Neonatal brain size and neurocranial dimensions in Pliocene hominids: implications for obstetrics. J. Hum. Evol. 16, 291-296.

1006

Lewin, R., Foley, R.A., 2004. Principles of Human Evolution. Blackwell, London.

1007

Martin, R., Saller, K., 1957. Lehrbuch der Anthropologie. Gustav Fischer, Stuttgart.

1008

Masao, F.T., Ichumbaki, E.B., Cherin, M., Barili, A., Boschian, G., Iurino, D.A., Menconero, S., Moggi-Cecchi, J., Manzi, G., 2016. New footprints from Laetoli (Tanzania) provide evidence for marked body size variation in early hominins. eLife 5, e19568.

McHenry, H.M., 1976. Early hominid body weight and encephalization. Am. J. Phys. Anthropol. 45, 77-83.

1013 McHenry, H.M., 1988. New estimates of body weight in early hominids and their significance to encephalization and megadontia in "robust" australopithecines. In: Grine, F.E. (Ed.), Evolutionary history of the "robust" australopithecines. Aldine Transaction, New Brunswick. pp. 133-48.

McHenry, H.M., 1991. Sexual dimorphism in Australopithecus afarensis. J. Human Evol. 20, 21-32.

1019 McHenry, H.M., 1992. Body size and proportions in early hominids. Am. J. Phys. Anthropol. 87, 407-431. McHenry, H.M., Berger, L.R., 1998. Body proportions in Australopithecus afarensis and A. africanus and the origin of the genus Homo. J. Human. Evol. 35, 1-22. 
1023 Meyer, M.R., 2005. Functional biology of the Homo erectus axial skeleton from Dmanisi, 1024 Georgia. PhD Thesis, University of Pennsylvania.

1025 Meyer, M.R., 2016. The Cervical Vertebrae of KSD-VP-1/1. In: Haile-Selassie, Y., Su,

1026 D.F. (Eds.), The Postcranial Anatomy of Australopithecus afarensis: New Insights from 1027 KSD-VP-1/1 (Vertebrate Paleobiology and Paleoanthropology). Springer, Dordrecht. Pp. $1028 \quad 63-112$.

1029

1030 Meyer, M.R., Williams, S.A., Smith, M.P., Sawyer, G.J., 2015. Lucy's back: Reassessment 1031 of fossils associated with the A.L. 288-1 vertebral column. J. Hum. Evol. 85, 1741032180.

1033 Millien, V., Bovy, H., 2010. When teeth and bones disagree: body mass estimation of a giant 1034 extinct rodent. J. Mammal. 91, 11-18.

1035 Nagano, A., Umberger, B.R., Marzke, M.W., Gerritsen, K.G., 2005. Neuromusculoskeletal 1036 computer modeling and simulation of upright, straight-legged, bipedal locomotion of 1037 Australopithecus afarensis (A.L. 288-1). Am. J. Phys. Anthropol. 126, 2-13.

1038 Niskanen, M., Junno, J.-A., 2009. Estimation of African apes' body size from postcranial 1039 dimensions. Primates 50, 211-220

1040 Organ, J.M., Ward, C.V. 2006. Contours of the hominoid lateral tibial condyle with 1041 implications for Australopithecus. J. Hum. Evol. 51, 113-127.

1042 Polk, J., 2004. Influences of limb proportions and body size on locomotor kinematics in 1043 terrestrial primates and fossil hominins. J. Hum. Evol. 47, 237-252.

1044 Porter, A.M., 1995. The body weight of A.L. 288-1 ('Lucy'): A new approach using estimates 1045 of skeletal length and the body mass index. Int. J. Osteoarchaeol. 5, 203-212.

1046 R Core Team, 2012. R: A language and environment for statistical computing. R Foundation 1047 for Statistical Computing, Vienna.

1048 Robinson, J.T., 1972. Early hominid posture and locomotion. University of Chicago 1049 Press, Chicago. 
1050 Rosset, A., Spadola, L., Ratib, O., 2004. OsiriX: an open-source software for navigating in 1051 multidimensional DICOM images. J. Digit. Imaging 17, 205-216.

1052 Ruff, C.B., 1994. Morphological adaptation to climate in modern and fossil hominids. Am. J. 1053 Phys. Anthropol. 37, 65-107.

1054 Ruff, C.B., 2000. Body mass prediction from skeletal frame size in elite athletes. Am. J. Phys. Anthropol. 113, 507-517.

1056 Ruff, C.B., 2002. Variation in human body size and shape. Annu. Rev. Anthropol. 31, 211232.

1058 Ruff, C.B., 2003. Long bone articular and diaphyseal structure in Old World monkeys and apes. II: Estimation of body mass. Am. J. Phys. Anthropol. 120, 16-37.

1060 Ruff, C.B., 2010. Body size and body shape in early hominins-implications of the Gona pelvis. J. Hum. Evol. 58, 166-178.

1062 Ruff, C.B., Scott, W.W., Liu, A.Y., 1991. Articular and diaphyseal remodeling of the proximal femur with changes in body mass in adults. Am. J. Phys. Anthropol. 86, 397-413.

1064 Ruff, C.B., Niskanen, M., Junno, J., Jamison, P., 2005. Body mass prediction from stature and bi-iliac breadth in two high latitude populations, with application to earlier higher latitude humans. J. Human Evol. 48, 381-392.

Ruff, C.B., Loring Burgess, M., Ketcham, R.A., Kappelman, J. 2016. Limb bone structural proportions and locomotor behaviour in A.L. 288-1 (“Lucy”). PLoS One 11,

1070 Ryan, T.M., Sukhdeo, S., 2016. KSD-VP-1/1: Analysis of the postcranial skeleton using high-resolution computed tomography. In Haile-Selassie, Y. and Su, D.G. (Eds.),

1074 Sanders, W.J., 1998. Comparative morphometric study of the australopithecine vertebral series Stw-H8/H41. J. Hum. Evol. 34, 249-302.

1076 Schlager, S., 2013. Soft-tissue reconstruction of the human nose - population differences and sexual dimorphism". PhD Thesis: Albert-Ludwigs-Universität Freiburg 
1078 Schmid, P., 1983. Ein Rekonstruktion des Skelettes von A.L. 288-1 (Hadar) und deren 1079 Konsequenzen. Folia Primatol. 40, 283-306.

1080 Schmid, P., Churchill, S.E., Nalla, S., Weissen, E., Carlson, K.J., de Ruiter, D.J., Berger, 1081 L.R., 2013. Mosaic morphology in the thorax of Australopithecus sediba. Science $1082 \quad 340,1234598$.

1083 Sellers, W.I., Dennis, L.A., Wang, W.J., Crompton, R.H., 2004. Evaluating alternative gait 1084 strategies using evolutionary robotics. J. Anat. 204, 343-351.

1085 Sellers, W.I., Cain, G.M., Wang, W., Crompton, R.H., 2005. Stride lengths, speed and 1086

Smith, R.J., 1994. Regression models for prediction equations. J. Hum. Evol. 26, 239-244.

1098 Smith, R.J., 2002. Estimation of body mass in paleontology. J. Hum. Evol. 43, 271-287.

1099 Smith, R.J., 2009. Use and misuse of the reduced major axis for line-fitting. Am. J. Phys.

$1100 \quad$ Anthropol. 140, 476-486.

1101 Stein, K., Csiki, Z., Rogers, K.C., Weishampel, D.B., Redelstorff, R., Carballido, J.L., Sander, M., 2010. Small body size and extreme cortical bone remodeling indicate phyletic dwarfism in Magyarosaurus dacus (Sauropoda: Titanosauria). PNAS. 107, 9258-9263. 
1105 Steudel-Numbers, K.L., 2006. Energetics in Homo erectus and other early hominins: the 1106 consequences of increased lower-limb length. J. Hum. Evol. 51, 445-453.

1107 Sutton, M., Rahman, I., Garwood, R., 2014. Techniques for virtual palaeontology. John $1108 \quad$ Wiley and Sons, Chichester.

1109 Symonds, M.R.E., Blomberg, S.P., 2014. A primer on phylogenetic generalized least 1110 squares. In Garamszegi, L.Z. (Ed.) Modern phylogenetic comparative methods and 1111 their application to evolutionary biology. Springer-Verlag, Berlin. p. 552.

1112 Syväranta, J., Lensu, A., Marjomäki, T.J., Oksanen, S., Jones, R.I., 2013. An empirical 1113 evaluation of the utility of convex hull and standard ellipse areas for assessing 1114 population niche widths from stable isotope data. PLoS One 8, e56094.

1115 Tague, R.G., 1989. Variation in pelvic size between males and females. Am. J. Phys. $1116 \quad$ Anthropol. 80, 59-71.

1117 Tague, R.G., Lovejoy, C.O., 1986. The obstetric pelvis of A.L. 288-1 (Lucy). J. Hum. Evol. $1118 \quad$ 15, 237-255.

1119 Treece, G.M., Prager R.W., Gee. A.H., 1999 Regularised marching tetrahedra: improved 1120 iso-surface extraction. Comp. Graph. 23, 583-598.

1121 Trinkaus, E., Ruff, C.B., 2012. Femoral and tibial diaphyseal cross-sectional geometry in 1122 Pleistocene Homo. Paleoanthropol. 2012, 13-62

1123 Vančata, V., 2005. A preliminary analysis of long bone measurements of Homo floresiensis: 1124 bone robusticity, body size, proportions and encephalisation. Anthropologie 43, 173$1125 \quad 182$.

1126 Wang, W., Crompton, R.H., Carey, T.S., Günther, M.M., Li, Y., Savage, R., Sellers, W.I., 1127 2004. Comparison of inverse-dynamics musculo-skeletal models of A.L. 288-1 1128 Australopithecus afarensis and KNM-WT 15000 Homo ergaster to modern humans, 1129 with implications for the evolution of bipedalism. J. Hum. Evol. 47, 453-478.

1130 Williams, S.A., Russo, G.A., 2015. Evolution of the Hominoid vertebral column: The long and 1131 the short of It. Evol. Anthropol: Issues News and Reviews 24(1):15-32 
1132 Williams, S.A., Russo, G.A., 2016. The fifth element (of Lucy's sacrum): Reply to Machnicki, 1133 Lovejoy, and Reno. Am J Phys Anthropol 161(2), 374-378.

1134 Williams, S.A. Ostrofsky, K.R., Frater, N., Churchill,S.E., Schmid,P., Berger, L.R. 2013. The vertebral column of Australopithecus sediba. Science 340(6129),1232996

1136 Williams, S.A., Middleton, E.R., Vilamil, C.I., Shattuck, M.R., 2016. Vertebral numbers and human evolution Am. J. Phys. Anthropol. 159(S61):S19-S36

1138 Zollikofer, C.P.E., Ponce de León, M., 2005. Virtual Reconstruction: A Primer in ComputerAssisted Paleontology and Biomedicine. Wiley, London. 


\section{$1140 \quad$ Figure legends}

1142 Figure 1. The convex hulling technique. A) Series of 500 points located in 2D space, B) the

114326 outermost points defining the convex hull are highlighted in red, C) the convex hull (red

1144 line) represents the minimum volume polygon that may be fitted around the data whilst

1145 remaining convex, D) a larger point cloud of $\sim 160,000$ points based on the isosurface of a

1146 Macaca skull, with 136 outermost points contributing to the form of the convex hull.

1148 Figure 2. The convex hulling approach applied to the Olive baboon (Papio anubis). Left)

1149 Isosurface of the skeleton extracted from the CT scan; Right) Closed manifold convex hulls 1150 around the extremities of the skeletal functional units, from which minimum skeletal volume 1151 is calculated.

1152

1153 Figure 3. Predicted body mass for Australopithecus afarensis (A.L. 288-1) over time. Where

1154 upper and lower bounds are included in a publication, they are represented by two data 1155 points. Mass estimates sourced from: Johansen and Edey (1981); Jungers (1982, 1988b, 1156 1990); Leutenegger (1987); McHenry (1988, 1991, 1992); Franciscus and Holliday (1992);

1157 Hartwig-Scherer (1993); Porter (1995); Ruff (2010); Squryres and Ruff (2015); Grabowski et 1158 al. (2015). Note, some of the above studies may incorporate previously published raw data 1159 or mass estimates into their own analyses, and as such may be non-independent. Values

1160 represent extreme upper and lower mass estimates of a given publication and do not

1161 necessarily reflect the authors' preference for which values may be most appropriate (see

1162 text). Points in red represent results of the present study.

1163

1164 Figure 4. Pelvis reconstruction. Left top, Cranial view, Right top, medial view, Left bottom, 1165 posterior view, Right bottom, anterior view. 
1167 Figure 5. Complete articulated model of A.L. 288-1 upon which convex hulling and mass

1168 estimation was conducted. Left, anterior view; right, lateral view.

1169

1170 Figure 6. A) Convex hull predictive model, in which $\log _{10}$ total convex hull volume $\left(\mathrm{m}^{3}\right)$ is

1171 plotted against $\log _{10}$ body mass $(\mathrm{kg})$. Line fitted using ordinary least squares (see Table 5 for

1172 details of the fitted equation). B) Primate consensus phylogeny sourced from 10kTrees

1173 (http://10ktrees.fas.harvard.edu/) used as a basis for phylogenetically corrected

1174 phylogenetically generalized least squares regression.

1175

1176 Figure 7. The relationship between percentage prediction error of the convex hull equation

1177 and body mass index (BMI) when applied to male humans. Green = 'healthy' BMI, yellow =

1178 'overweight' BMI, red = 'obese' BMI. BMI calculated as mass $(\mathrm{kg}) /$ height $(\mathrm{m})^{2}$.

1179

1180 Figure 8. The complete Australopithecus afarensis reconstruction with convex hulls fitted.

1181

1182 Figure 9. A sensitivity analysis of the effect of uncertainty in the size of the trunk region

1183 upon body mass estimates. From left to right; original articulated trunk model (light blue),

1184 trunk expanded $10 \%$ in dorsoventral and mediolateral extent (green), trunk expanded $20 \%$ in

1185 dorsoventral and mediolateral extent (purple).

1186 
Table 1. A range of mass estimates derived for A.L. 288-1 based upon various skeletal elements. $^{\text {a }}$

\section{Predicted body mass $(\mathrm{kg})$}

\section{Skeletal element}

Elbow

Radial head

Thoracic vertebra 12

Sacrum

Femoral head

Femoral shaft

Proximal tibia

Distal tibia

Talus
Humeral head

\section{All Hominoidea}

17.4

16.5

12.9

24.1

28.5

27.9

35.2

32.2

27.1

37.0

\section{Homo sapiens}

27.3

30.7

28.2

32.5

17.0

27.9

37.1

27.8

24.4

${ }^{a}$ Values taken from McHenry (1992) for ordinary least squares regression models. For definitions of the dimensions measured from each skeletal element, see McHenry (1992). The data highlight the sensitivity of the traditional bivariate mass estimation approach to the skeletal element upon which the predictive model is based. 
Table 2. Convex hull specimen list and calculated convex hull (qhull) volumes. ${ }^{a}$

\begin{tabular}{|c|c|c|c|c|}
\hline Species & Common name & Source & Body mass (kg) & qhull Volume $\left(\mathrm{m}^{3}\right)$ \\
\hline Homo sapiens & Human & NLM & 68.9 & $4.91 \times 10^{-2}$ \\
\hline Pongo pygmaeus & Orangutan & - & 45.0 & $3.25 \times 10^{-2}$ \\
\hline Pan troglodytes & Chimpanzee & - & $50.9^{b}$ & $4.18 \times 10^{-2}$ \\
\hline Gorilla gorilla & Gorilla & KUPRI & 176.0 & $9.57 \times 10^{-2}$ \\
\hline Hylobates lar & Lar gibbon & KUPRI & $6.65^{b}$ & $6.60 \times 10^{-3}$ \\
\hline Hylobates agilis & Agile gibbon & KUPRI & 6.75 & $5.40 \times 10^{-3}$ \\
\hline Saimiri sciureus & Squirrel monkey & KUPRI & 0.759 & $6.00 \times 10^{-4}$ \\
\hline Macaca fuscata & Japanese macaque & KUPRI & 6.60 & $5.10 \times 10^{-3}$ \\
\hline Chlorocebus aethiops & Grivet monkey & KUPRI & 3.78 & $3.70 \times 10^{-3}$ \\
\hline Hylobates pileatus & Pileated gibbon & NMS & 7.40 & $4.95 \times 10^{-3}$ \\
\hline Alouatta caraya & $\begin{array}{c}\text { Black howler } \\
\text { monkey }\end{array}$ & NMS & 5.40 & $3.31 \times 10^{-3}$ \\
\hline $\begin{array}{l}\text { Trachypithecus } \\
\text { cristatus }\end{array}$ & Silvery langur & NMS & 7.50 & $3.83 \times 10^{-3}$ \\
\hline Cebus apella & Brown capuchin & NMS & 1.56 & $1.15 \times 10^{-3}$ \\
\hline Leontopithecus rosalia & Golden lion tamarin & NMS & 0.425 & $3.18 \times 10^{-4}$ \\
\hline Papio anubis & Olive baboon & NMS & 15.0 & $1.23 \times 10^{-2}$ \\
\hline \multicolumn{5}{|c|}{${ }^{\mathrm{a}} \mathrm{NLM}=$ National Library of Medicine, KUPRI = Kyoto University Primate Research Institute, } \\
\hline
\end{tabular}


that 11 of the 15 individuals included have body masses of less than $15 \mathrm{~kg}$, and thus fall considerably below the likely body mass of A.L. 288-1. 
Table 3. Obstetric dimensions and indices of pelvic reconstruction compared with other female fossil and extant hominin pelves. ${ }^{a}$
A.L. 288-1
A.L. $\quad \mathrm{MH} 2$
STS15
BSN49P27
$H$.
$P$.

\begin{tabular}{|c|c|c|c|c|c|c|c|}
\hline Au. afarensis & 2881 & $A u$. & $A u$. & Homo sp. & sapiens & troglodytes & \\
\hline This & $A u$. & sediba & africanus & & Mean & Mean & S.D. \\
\hline
\end{tabular}

reconstruction afarensis

\begin{tabular}{lcccccccccc}
\hline Bi-iliac breadth (BIB) & 264 & $268.3^{*}$ & 250 & 256.3 & 288 & 259.5 & 16.4 & 122.4 \\
Bi-acetabular diameter & & & & & & & \\
(BAD) & 114.1 & $118^{*}$ & 122.3 & 107.5 & 131 & 123.2 & 6.5 & 105.8 & 35.6 \\
BIB/BAD & 1.96 & 2.27 & 2.04 & 2.38 & 2.2 & 2.1 & 0.13 & 1.16 & 13.1 \\
Inlet SD & 80 & 76 & 81.7 & 83 & 98 & 105.2 & 19.1 & 143.7 & 12.6 \\
Inlet TD & 128.5 & 132 & 117.6 & 116.8 & 124.5 & 131.6 & 10.4 & 100 & 12.3 \\
Inlet SD/TD index & 62.3 & 57.6 & 69.5 & 71.1 & 78.7 & 80 & 17.4 & 146.1 & 20.1 \\
Midplane SD & 103.6 & - & 97.9 & - & - & 125.1 & 16 & 137.5 & 26.8 \\
Outlet SD & 85.8 & 71 & 97.4 & - & - & 119.4 & 17.8 & 122.4 & 9.6 \\
Subpubic angle & $77^{\circ}$ & $81^{\circ}$ & $76^{\circ}$ & $107.2^{\circ}$ & $110^{\circ}$ & $89.6^{\circ}$ & $12.3^{\circ}$ & -
\end{tabular}

${ }^{a}$ All A.L. 288-1 measurements are from Tague and Lovejoy (1986) except $\left({ }^{\star}\right)$, which were absent from this publication. These are therefore taken from Berge and Goularas (2010) (who measured Schmid's (1983) reconstruction of A.L. 288-1). BSN49P27 dimensions are from 
Simpson et al. (2010). Homo sapiens measurements from Tague (1989). MH2, STS15, and Pan troglodytes from Kibii et al. (2011).

SD=Saggital Diameter, TD = Transverse Diameter 
Table 4. Additional measurements of the pelvic reconstruction. ${ }^{a}$

Dimension Measurement (mm)

\begin{tabular}{lc}
\hline Midplane saggital diameter & 97.1 \\
False pelvis transverse diameter & 255.7 \\
Midplane posterior space & 71.2 \\
Outlet posterior space & 88.0 \\
Midplane anterior space & 77.5 \\
Sacral breadth & 86.4 \\
Total sacral height & 73.8 \\
\hline${ }^{a}$ All measurements following Tague (1989), except total sacral height.
\end{tabular}


Table 5. Measurements of long bones of A.L. 288-1. ${ }^{a}$

\begin{tabular}{ll}
\hline Element & Length $(\mathrm{mm})$ \\
\hline Ulna & 223 \\
Radius & 203 \\
Tibia & 225 \\
Fibula & 280 \\
Femur & 104 \\
Clavicle & 237 \\
Humerus & \\
\hline all elements are from the right side apart from the femur, which has been mirrored. \\
Measurements are from reconstructed scans (femur, tibia) and 3D prints of reconstructions \\
(all others).
\end{tabular}


Table 6. Posterior vertical heights (in mm) of vertebral bodies in Homo sapiens, Pan troglodytes, Australopithecus afarensis, Australopithecus africanus, Australopithecus sediba, and Homo erectus. ${ }^{\text {a }}$

\begin{tabular}{|c|c|c|c|c|c|c|c|c|c|c|c|c|c|c|c|c|c|c|c|c|c|c|c|c|c|}
\hline Sample & Vertebra & C1 & C2 & C3 & C4 & C5 & C6 & C7 & T1 & T2 & T3 & T4 & T5 & T6 & T7 & T8 & T9 & T10 & T11 & T12 & L1 & L2 & L3 & L4 & L5 \\
\hline \multirow[t]{3}{*}{ Andaman $^{(1)}$} & $n$ & - & - & 8 & 7 & 7 & 9 & 8 & 7 & 9 & 9 & 9 & 9 & 9 & 9 & 8 & 9 & 9 & 7 & 7 & 8 & 9 & 10 & 10 & 10 \\
\hline & Body height & - & - & 10.21 & 10.23 & 10.64 & 10.78 & 11.91 & 14.05 & 15.10 & 15.29 & 15.24 & 16.02 & 16.28 & 17.44 & 17.49 & 17.96 & 19.32 & 21.05 & 22.35 & 22.25 & 23.67 & 23.76 & 23.16 & 21.32 \\
\hline & Body height SD & - & - & 1.12 & 1.22 & 1.10 & 1.04 & 0.91 & 1.09 & 1.25 & 1.28 & 1.45 & 1.38 & 1.57 & 1.39 & 1.42 & 1.17 & 1.99 & 1.99 & 2.04 & 2.27 & 1.81 & 1.69 & 1.99 & 3.29 \\
\hline \multirow{3}{*}{$\begin{array}{l}\text { Homo } \\
\text { sapiens }^{(2)}\end{array}$} & $n$ & - & 23 & 23 & 23 & 23 & 23 & 23 & 23 & 23 & 23 & 23 & 23 & 23 & 23 & 23 & 23 & 23 & 23 & 23 & 23 & 23 & 23 & 23 & 23 \\
\hline & Body height & - & 36.91 & 11.64 & 11.59 & 12.38 & 12.32 & 13.31 & 16.59 & 17.45 & 17.45 & 18.55 & 18.69 & 19.28 & 20.29 & 20.67 & 21.90 & 22.30 & 23.92 & 24.97 & 26.24 & 26.37 & 25.95 & 25.77 & 23.90 \\
\hline & Body height SD & - & 1.81 & 1.29 & 1.05 & 1.16 & 1.23 & 2.14 & 1.48 & 1.67 & 1.39 & 1.85 & 2.12 & 2.25 & 1.61 & 2.37 & 2.14 & 2.25 & 2.32 & 2.15 & 2.67 & 2.30 & 2.63 & 2.08 & 2.61 \\
\hline \multirow{3}{*}{$\begin{array}{l}\text { Pan } \\
\text { troglodytes }^{(3)}\end{array}$} & $n$ & 25 & 25 & 25 & 25 & 25 & 25 & 25 & 25 & 25 & 25 & 25 & 25 & 25 & 25 & 25 & 25 & 25 & 25 & 25 & 25 & 25 & 25 & 25 & - \\
\hline & Body height & 33.75 & 11.53 & 11.91 & 12.23 & 12.71 & 12.54 & 13.64 & 14.91 & 15.61 & 15.49 & 15.44 & 15.75 & 15.58 & 15.61 & 15.69 & 16.10 & 17.25 & 18.79 & 21.46 & 25.60 & 26.52 & 26.44 & 26.42 & - \\
\hline & Body height SD & 4.27 & 2.79 & 2.04 & 1.89 & 2.16 & 2.02 & 2.07 & 1.95 & 1.75 & 2.24 & 2.12 & 2.19 & 2.10 & 2.12 & 1.76 & 2.04 & 2.10 & 2.68 & 2.68 & 2.95 & 3.30 & 3.31 & 3.17 & - \\
\hline A.L. $288.1^{(4)}$ & & - & - & - & - & - & - & - & - & - & - & - & - & 13.3 & - & 13.6 & $p$ & 14.4 & 16.1 & $p$ & - & - & 21.6 & - & - \\
\hline A.L. $288.1^{(5)}$ & & - & - & - & - & - & - & - & - & - & - & - & - & 13.3 & 13.6 & $p$ & 14.4 & 16.1 & $p$ & - & - & $p$ & 21.6 & & \\
\hline STS14 ${ }^{(6)}$ & & - & - & - & - & - & - & - & - & - & 12.3 & 12.8 & 13.3 & 13.6 & 14 & 14.6 & 15.4 & 16.8 & 19.1 & 19.6 & 19.9 & 19.5 & 19.1 & 17.3 & 16.8 \\
\hline $\mathrm{MH}^{(7)}$ & & - & - & - & - & - & - & - & - & - & - & - & - & & - & - & - & - & - & - & 17.1 & - & 15.7 & - & - \\
\hline $\mathrm{MH}^{(7)}$ & & - & - & - & - & - & - & - & - & - & - & - & 11.5 & 12.5 & - & - & - & - & - & - & - & - & - & 21.5 & 17.4 \\
\hline STW $431^{(8)}$ & & - & - & - & & - & - & - & - & - & - & - & - & & - & - & & - & - & & 23.9 & 24.3 & 23.9 & 22.5 & 19.8 \\
\hline STW8/41 ${ }^{(8)}$ & & - & - & - & - & - & - & - & - & - & - & - & - & - & - & - & - & - & - & - & 24.8 & 24.4 & 23.2 & - & 19 \\
\hline SK853/3981 ${ }^{(8)}$ & & - & - & - & - & - & - & - & - & - & - & - & - & - & - & - & - & - & - & - & - & 15.2 & - & - & - \\
\hline KSDVP1/1 ${ }^{(8)}$ & & - & - & 11.4 & 13.6 & 13.8 & 13.1 & - & - & - & - & - & - & & - & - & & - & - & & - & 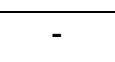 & & - & 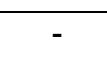 \\
\hline KNMWT15000 $^{(9)}$ & & - & - & - & - & - & - & 8.7 & 1.5 & 11.4 & 11.6 & - & 11.8 & 12.7 & 12.8 & - & - & - & 15.5 & - & 17.3 & 19.7 & 17.1 & 15.8 & 14.9 \\
\hline $\operatorname{Dmanisi}^{(10)}$ & & 6.9 & $29.9 / 14.74$ & 12.7 & - & - & - & - & - & - & 17.2 & - & - & - & - & - & - & - & 24 & - & - & 26.6 & - & - & - \\
\hline
\end{tabular}

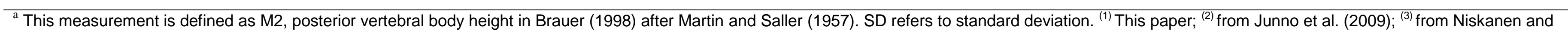

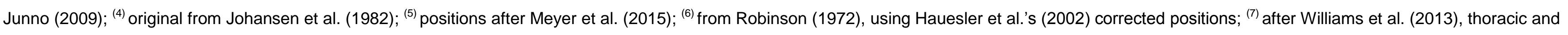
cervical heights measured from scans, this paper; ${ }^{(8)}$ after Meyer (2016); ${ }^{(9)}$ after Latimer and Ward (1993); ${ }^{(10)}$ D2673, D2721, D2715, D2672, from Meyer (2005) and Mayer et al. (2015). 
Table 7. Reconstructed spine heights using proportions from modern comparative samples. ${ }^{a}$

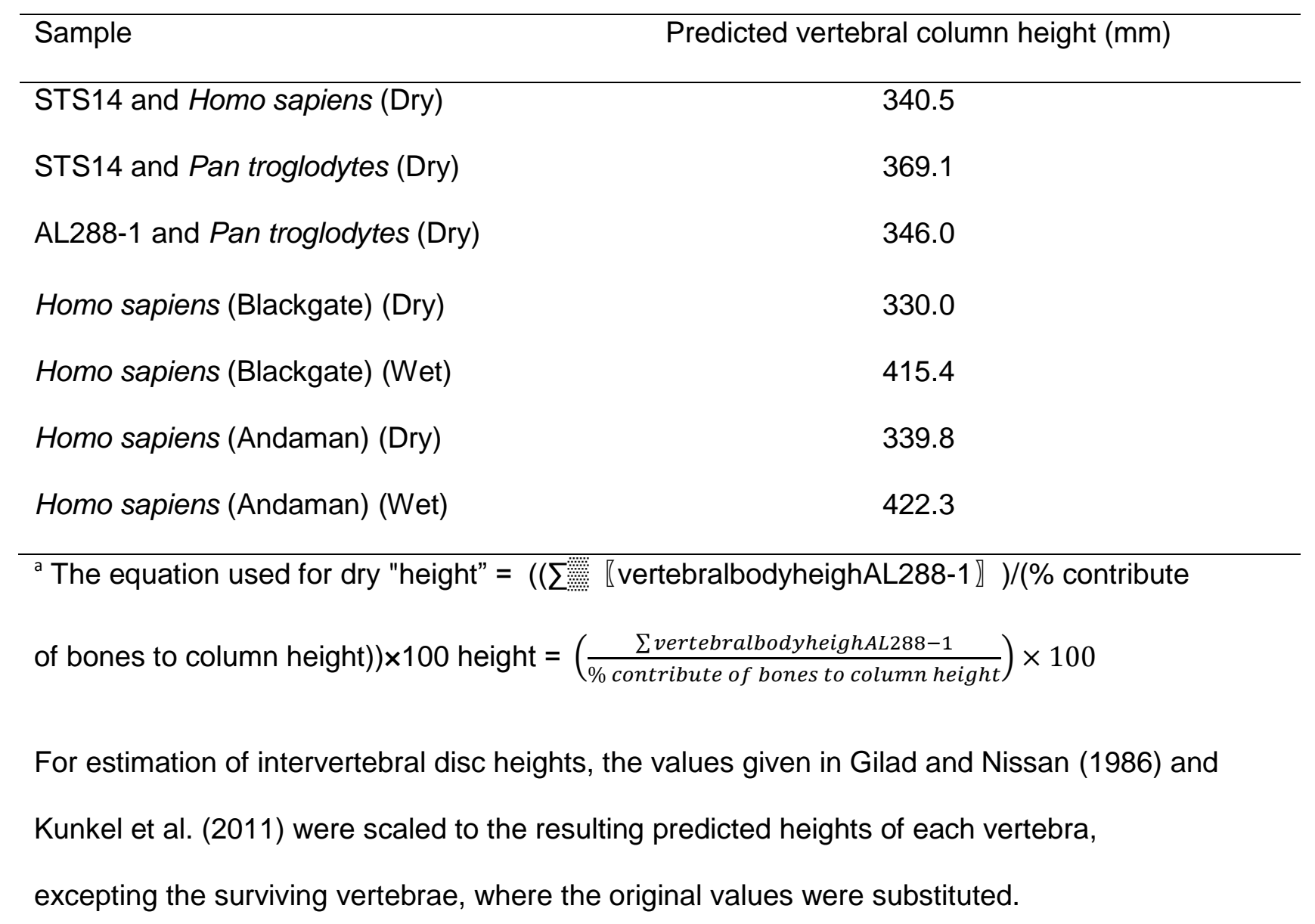


Table 8. Ordinary least squares (OLS), reduced major axis (RMA), and phylogenetic generalized least squares (PGLS) regressions of $\log _{10}$ total convex hull volume $\left(\mathrm{m}^{3}\right)$ against $\log _{10}$ body mass $(\mathrm{kg})$. $^{\mathrm{a}}$

\begin{tabular}{lcccccc}
\hline Fit & $\mathbf{a}$ & $\mathbf{a} \pm 95 \%$ & $\mathbf{b}$ & $\mathbf{b} \pm 95 \%$ & $\mathbf{r}^{2}$ & $\%$ SEE \\
\hline OLS & 3.17 & $3.02-3.33$ & 1.02 & $0.95-1.09$ & 0.988 & 20.3 \\
RMA & 3.19 & $3.04-3.34$ & 1.03 & $0.96-1.09$ & 0.988 & 13.8 \\
PGLS & 3.32 & $2.96-3.67$ & 1.07 & $0.94-1.20$ & $*$ & 25.5 \\
\hline
\end{tabular}

${ }^{a} \pm 95 \%=95 \%$ confidence intervals of the slope and intercept, \%SEE = percentage standard error of the estimate. \%SEE on logged data OLS regression was calculated as $\left.10^{\wedge}\left(\log _{10}(100)+S E E\right)\right) . \%$ SEE for RMA regression was based on residuals calculated according to Organ and Ward (2006).

*The OLS definition of $r^{2}$ does not easily carry over to PGLS. Rather than reporting a "pseudo $r^{2}$, we err on the side of caution and do not report $r^{2}$ (Symonds and Blomberg, 2014). 
Table 9. Modern primate specimens used to test the accuracy of the convex hull (qhull) predictive equation. ${ }^{\text {a }}$

\begin{tabular}{|c|c|c|c|c|c|c|c|c|c|}
\hline Species & Common name & Source & Accession number & Sex & BMI & $\begin{array}{c}\text { Body } \\
\text { mass (kg) }\end{array}$ & $\begin{array}{l}\text { qHull volume } \\
\qquad\left(\mathrm{m}^{3}\right)\end{array}$ & $\begin{array}{c}\text { qHull mass } \\
(\mathrm{kg})\end{array}$ & $\begin{array}{c}\% \\
\text { difference }\end{array}$ \\
\hline $\begin{array}{l}\text { Aotus } \\
\text { trivirgatus }\end{array}$ & $\begin{array}{l}\text { Three striped night } \\
\text { monkey }\end{array}$ & KUPRI & 1322 & $M$ & & 1.03 & $8.31 \times 10^{-4}$ & 1.06 & $2.81 \%$ \\
\hline $\begin{array}{l}\text { Saimiri } \\
\text { sciureus }\end{array}$ & Squirrel monkey & KUPRI & 287 & M & & 0.62 & $4.32 \times 10^{-4}$ & 0.54 & $13.3 \%$ \\
\hline $\begin{array}{l}\text { Saimiri } \\
\text { sciureus }\end{array}$ & Squirrel monkey & KUPRI & 283 & M & & 0.71 & $6.37 \times 10^{-4}$ & 0.81 & $13.4 \%$ \\
\hline $\begin{array}{l}\text { Saimiri } \\
\text { sciureus }\end{array}$ & Squirrel monkey & KUPRI & 280 & $M$ & & 0.86 & $6.51 \times 10^{-4}$ & 0.83 & $4.40 \%$ \\
\hline $\begin{array}{l}\text { Macaca } \\
\text { fuscata }\end{array}$ & Japanese macaque & KUPRI & 897 & $\mathrm{~F}$ & & 4.50 & $2.57 \times 10^{-3}$ & 3.36 & $29.0 \%$ \\
\hline $\begin{array}{l}\text { Macaca } \\
\text { fuscata }\end{array}$ & Japanese macaque & KUPRI & 369 & $\mathrm{~F}$ & & 10.2 & $5.86 \times 10^{-3}$ & 7.77 & $27.0 \%$ \\
\hline Homo sapiens & Human & TCIA & $\begin{array}{c}\text { NaF-PROSTATE-01- } \\
0005\end{array}$ & M & 21.4 & 68.7 & $4.93 \times 10^{-2}$ & 69.5 & $1.14 \%$ \\
\hline Homo sapiens & Human & TCIA & $\begin{array}{c}\text { NaF-PROSTATE-01- } \\
0007\end{array}$ & M & 24.0 & 82.2 & $5.20 \times 10^{-2}$ & 73.4 & $10.7 \%$ \\
\hline Homo sapiens & Human & TCIA & $\begin{array}{c}\text { NaF-PROSTATE-01- } \\
0009\end{array}$ & M & 24.4 & 90.1 & $5.43 \times 10^{-2}$ & 76.8 & $14.8 \%$ \\
\hline Homo sapiens & Human & TCIA & $\begin{array}{c}\text { NaF-PROSTATE-01- } \\
0003\end{array}$ & M & 26.9 & 82.5 & $4.57 \times 10^{-2}$ & 64.4 & $21.9 \%$ \\
\hline
\end{tabular}




\begin{tabular}{|c|c|c|c|c|c|c|c|c|c|}
\hline Homo sapiens & Human & TCIA & $\begin{array}{c}\text { NaF-PROSTATE-01- } \\
0002\end{array}$ & M & 29.2 & 91.5 & $4.72 \times 10^{-2}$ & 66.6 & $27.2 \%$ \\
\hline Homo sapiens & Human & TCIA & $\begin{array}{c}\text { NaF-PROSTATE-01- } \\
0006\end{array}$ & $M$ & 31.7 & 88.5 & $4.28 \times 10^{-2}$ & 60.2 & $32.0 \%$ \\
\hline
\end{tabular}

${ }^{a}$ In one instance, the predictive model overestimated live body mass, whilst in three instances the model underestimated live model mass. $\mathrm{TCIA}=$ The Cancer Imaging Archive; $\mathrm{BMI}=$ body mass index, calculated as $\operatorname{mass}(\mathrm{kg}) / \mathrm{height}(\mathrm{m})^{2} . \mathrm{M}=\mathrm{male} ; \mathrm{F}=$ female. 
Table 10. Segmental convex hull (qhull) volumes calculated for the articulated model of Australopithecus afarensis. ${ }^{a}$

\begin{tabular}{lc}
\hline Body segment & qhull Volume $\left(\mathbf{m}^{3}\right)$ \\
\hline Skull & 0.001175 \\
Neck & 0.000140 \\
Trunk & 0.010573 \\
$+10 \%$ trunk & 0.012794 \\
$+20 \%$ trunk & 0.015225 \\
Upper arm & 0.000179 \\
Lower arm & 0.000117 \\
Hand & 0.000233 \\
Thigh & 0.000530 \\
Shank & 0.000299 \\
Foot & 0.000111 \\
\hline Total volume including trunk & 0.014826 \\
\hline Total volume including $+10 \%$ trunk & 0.017047 \\
\hline Total volume including $+20 \%$ trunk & 0.019478
\end{tabular}

${ }^{\mathrm{a}}$ Values for limb segments refer to one side of the body only. 
A
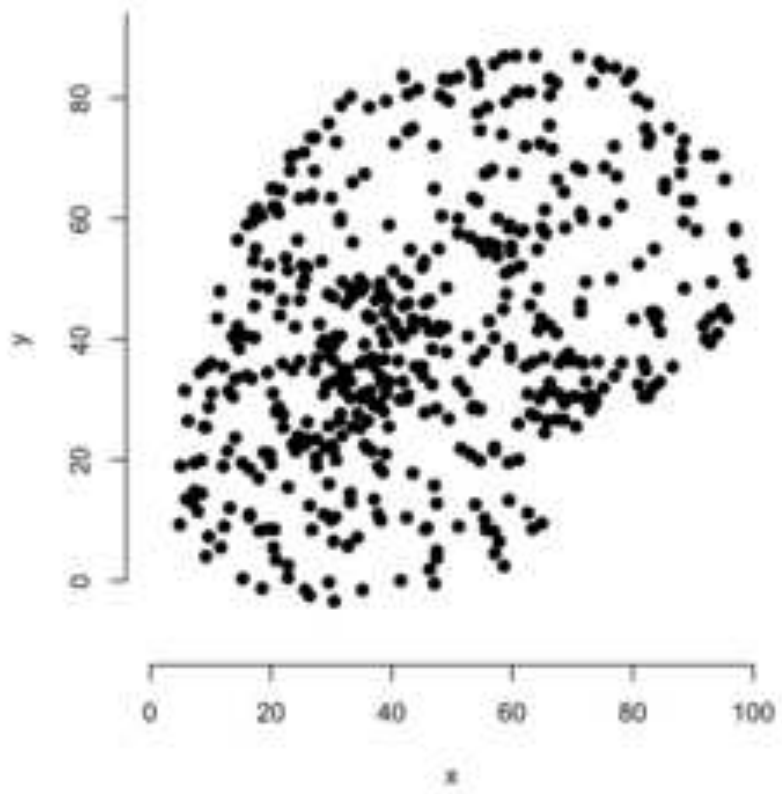

c
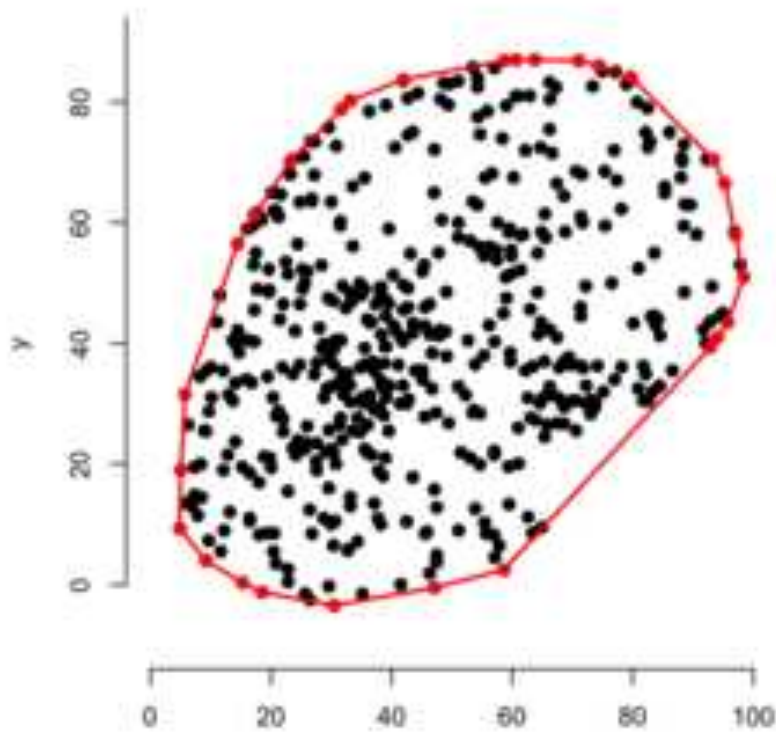

B
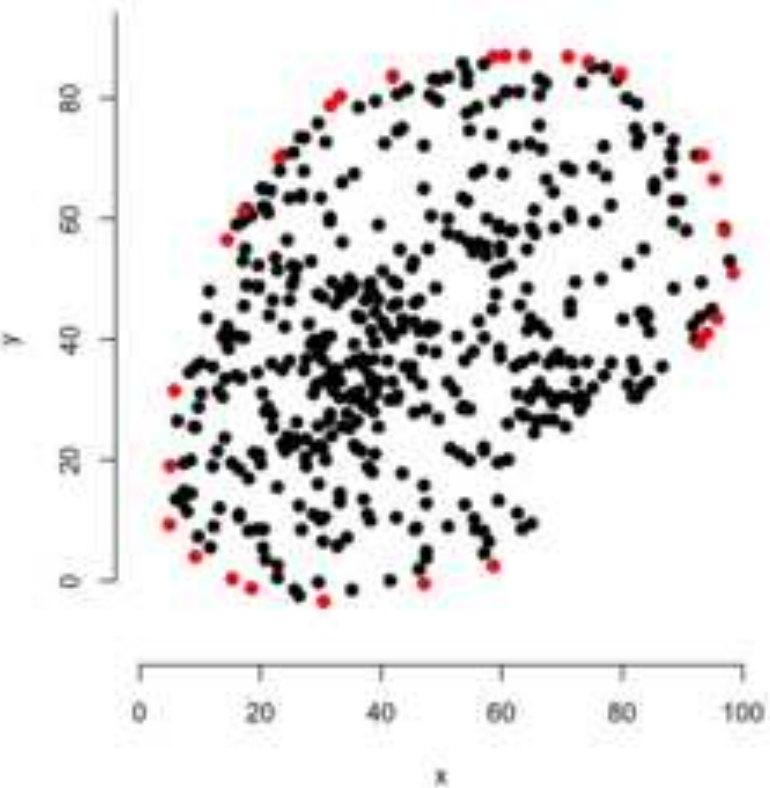

D
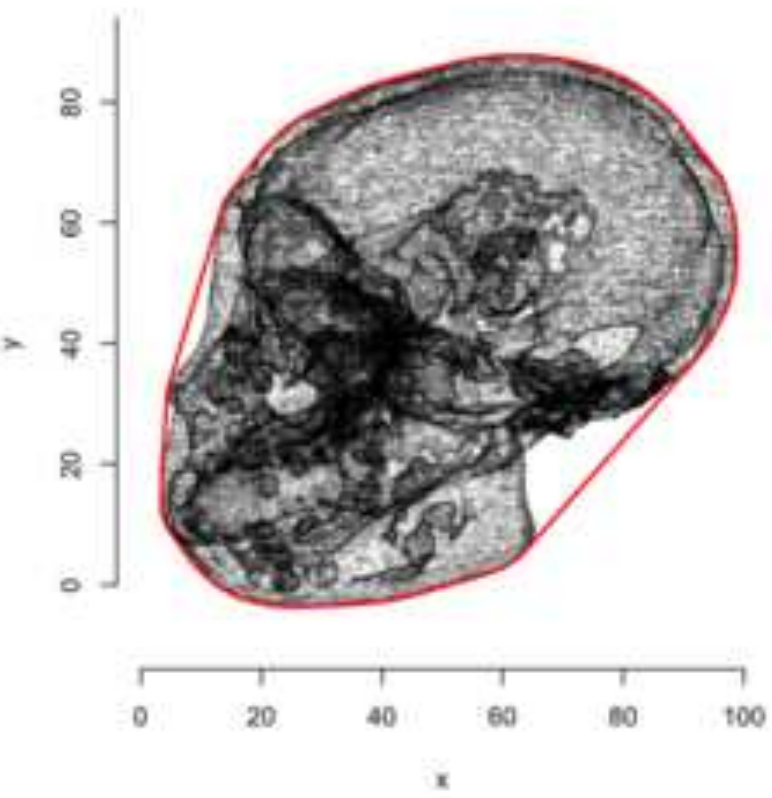
Click here to download high resolution image
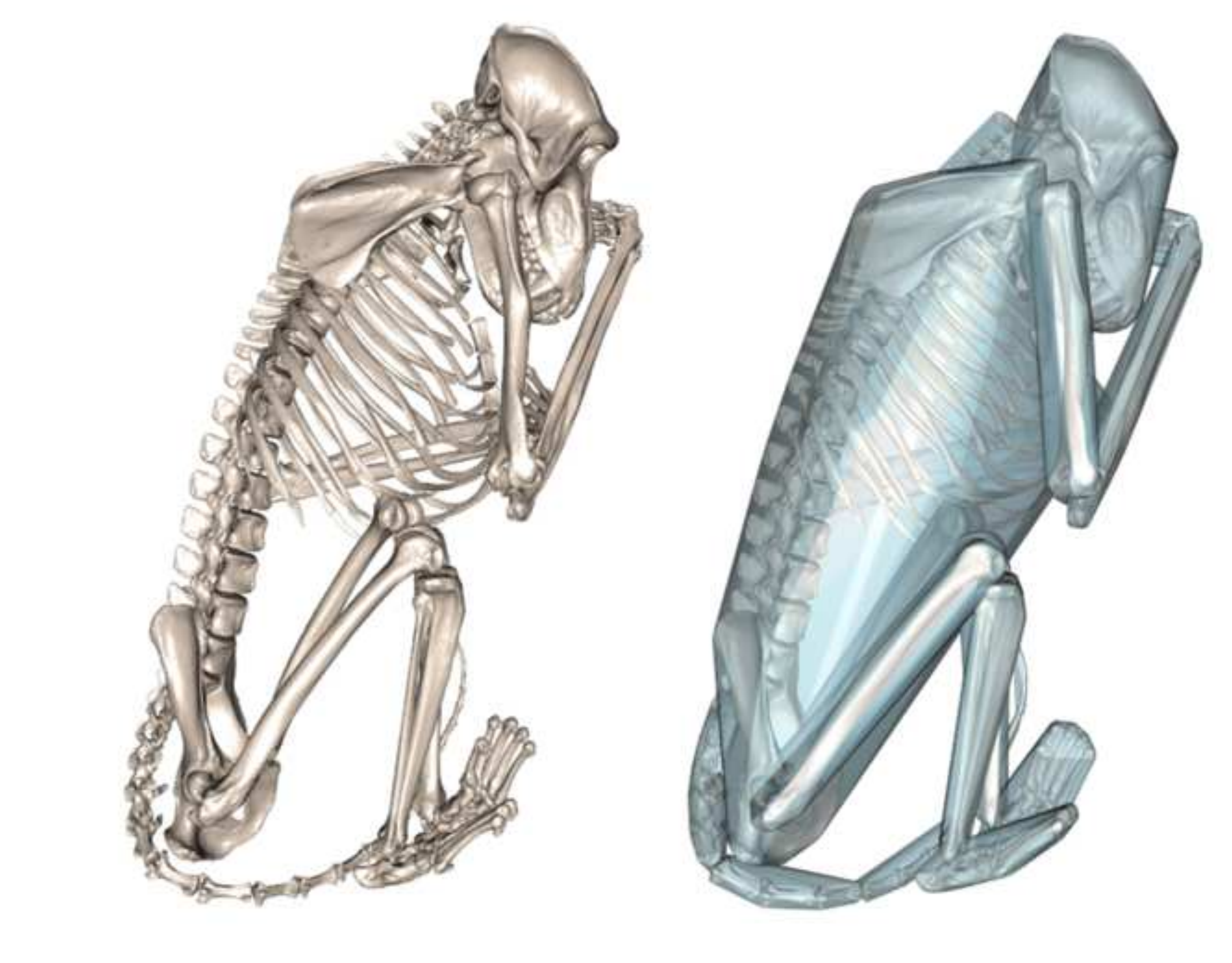

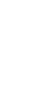

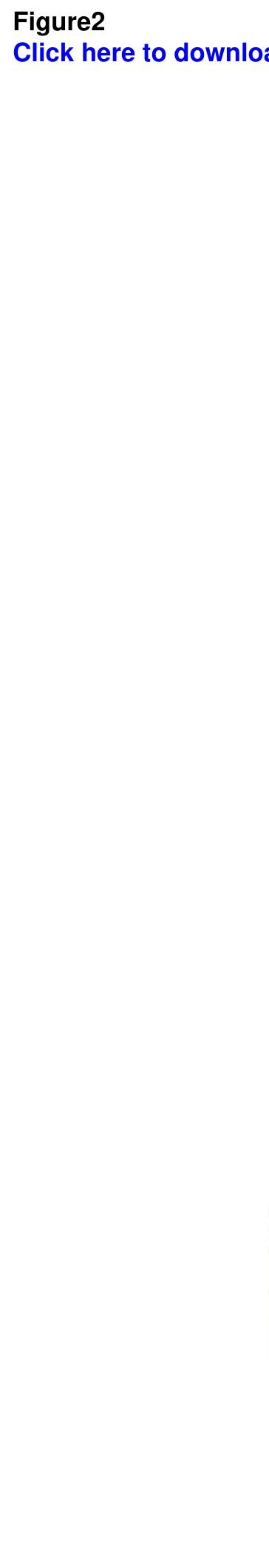
ge

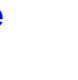
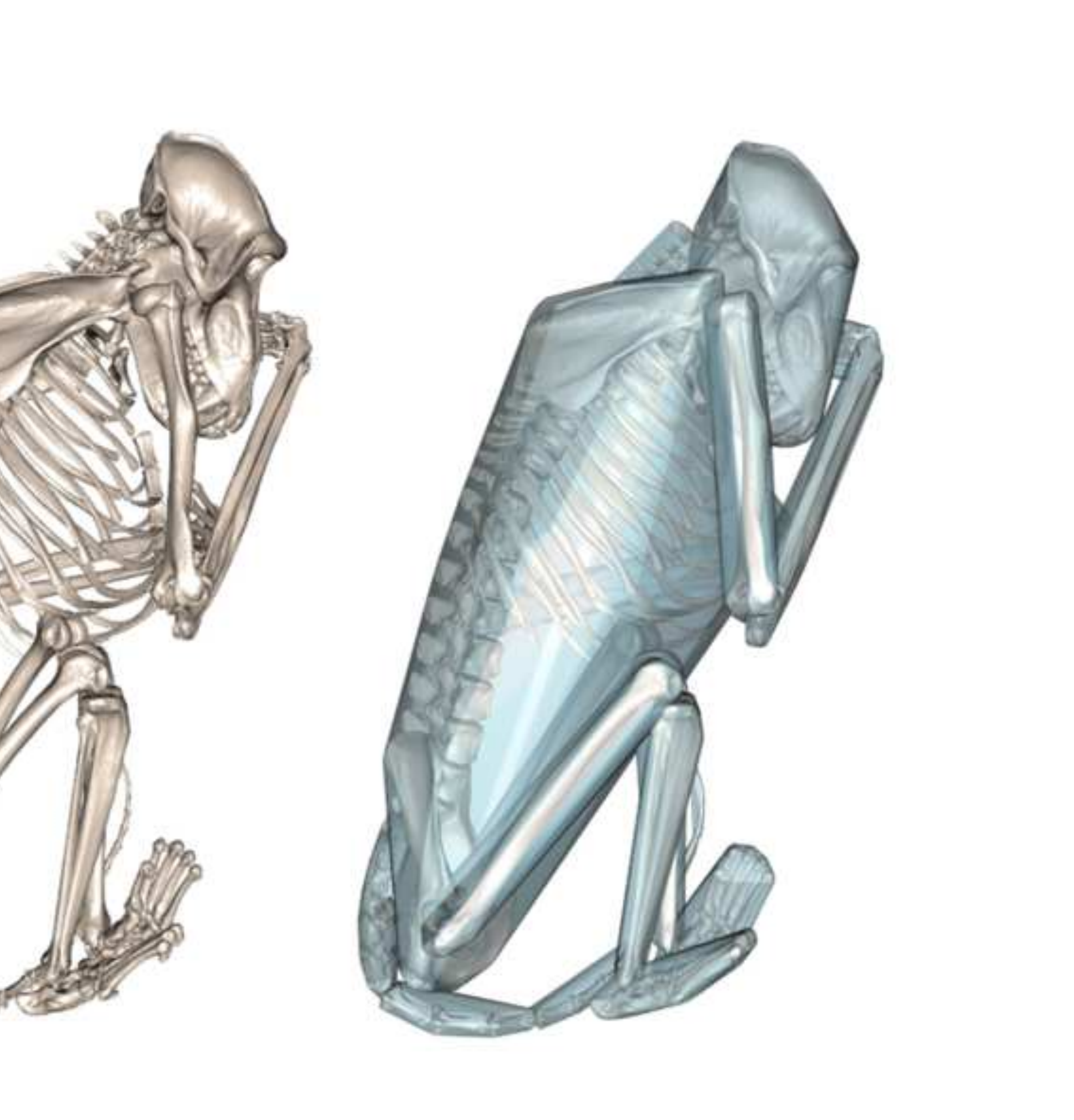

$$
\text { - }
$$
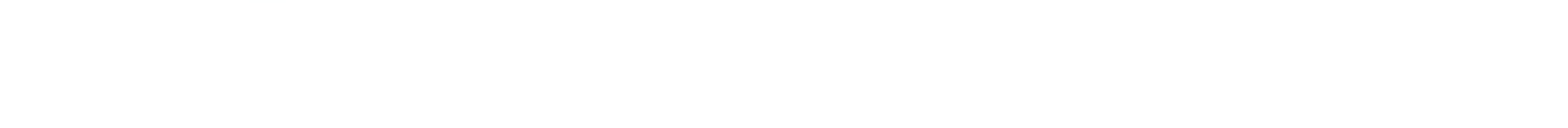


\section{Lucy (A.L. 288-1) mass estimates through time}

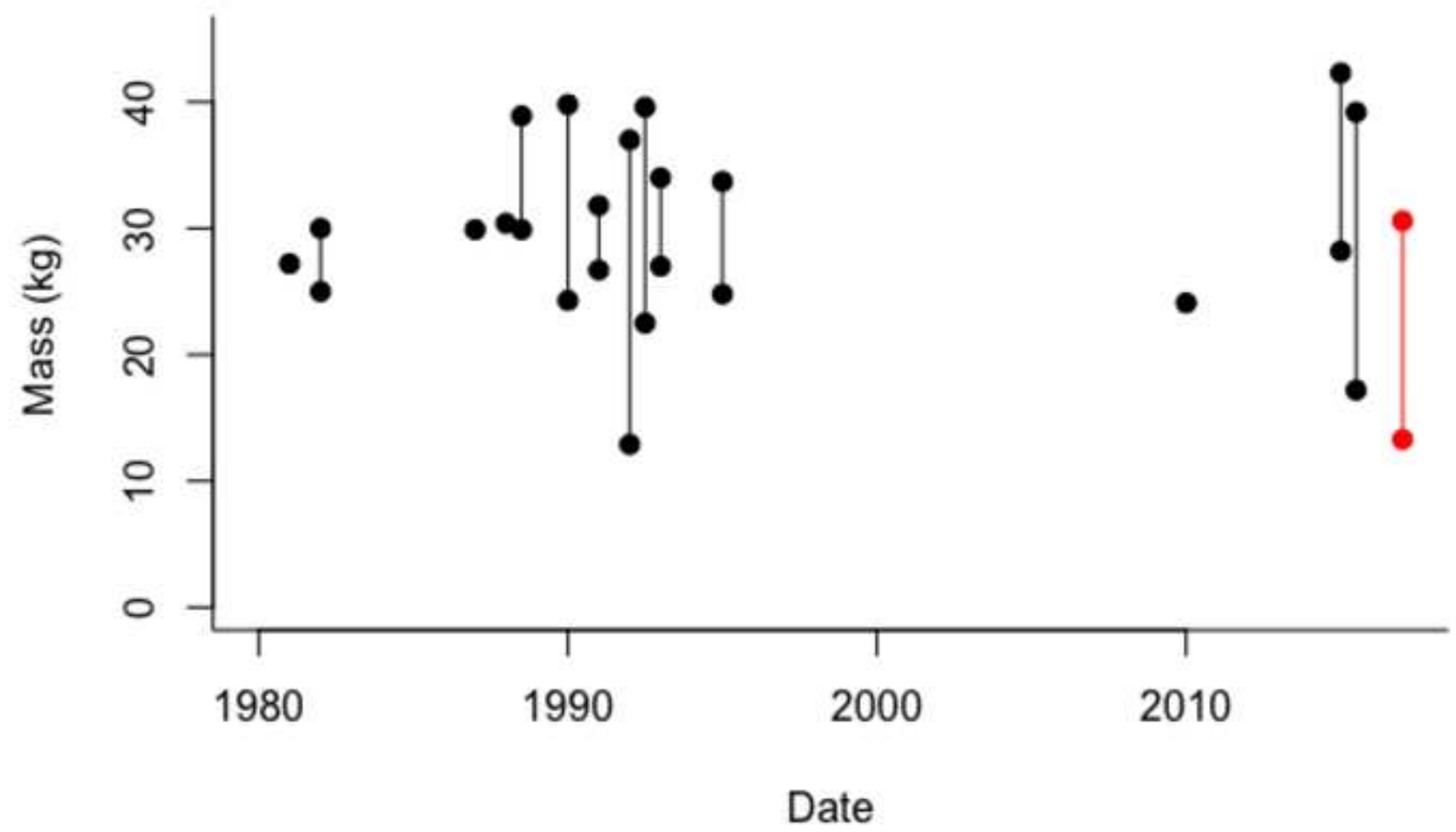


Click here to download high resolution image

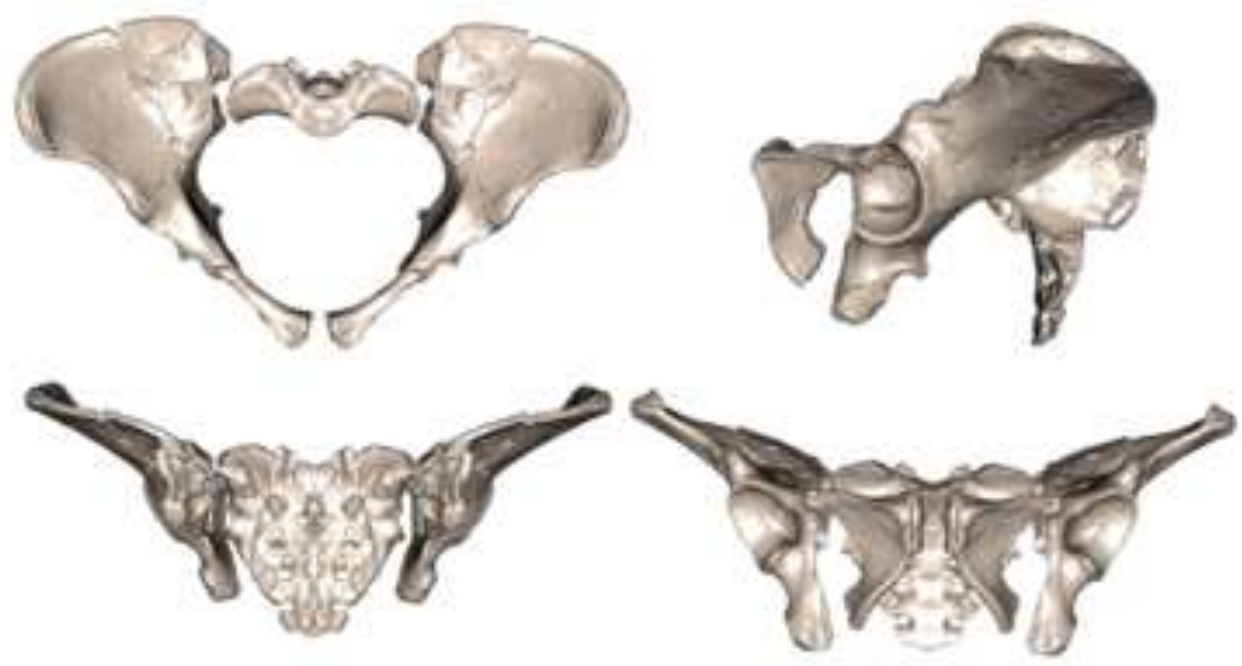


Figure5

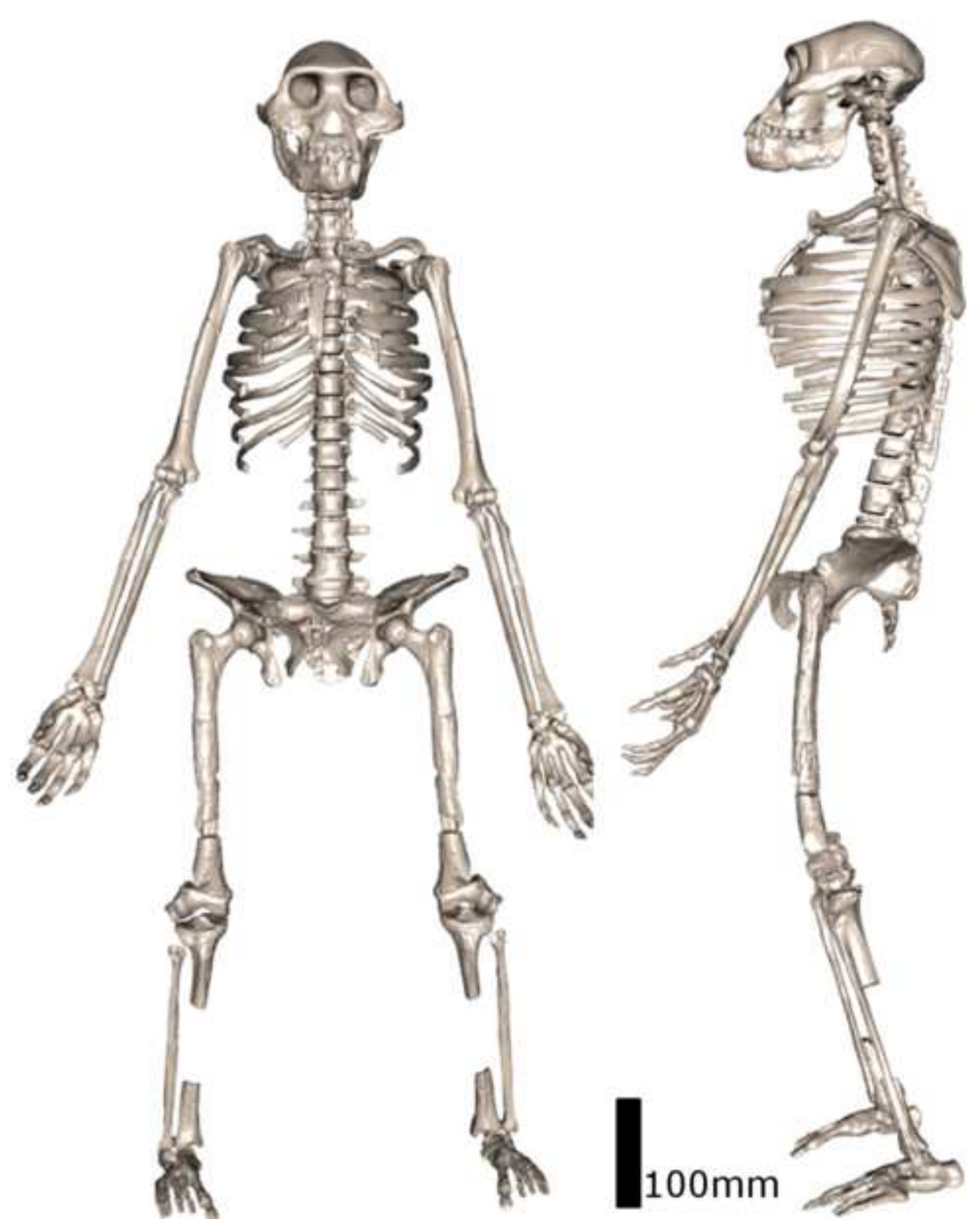

Click here to download high resolution image 

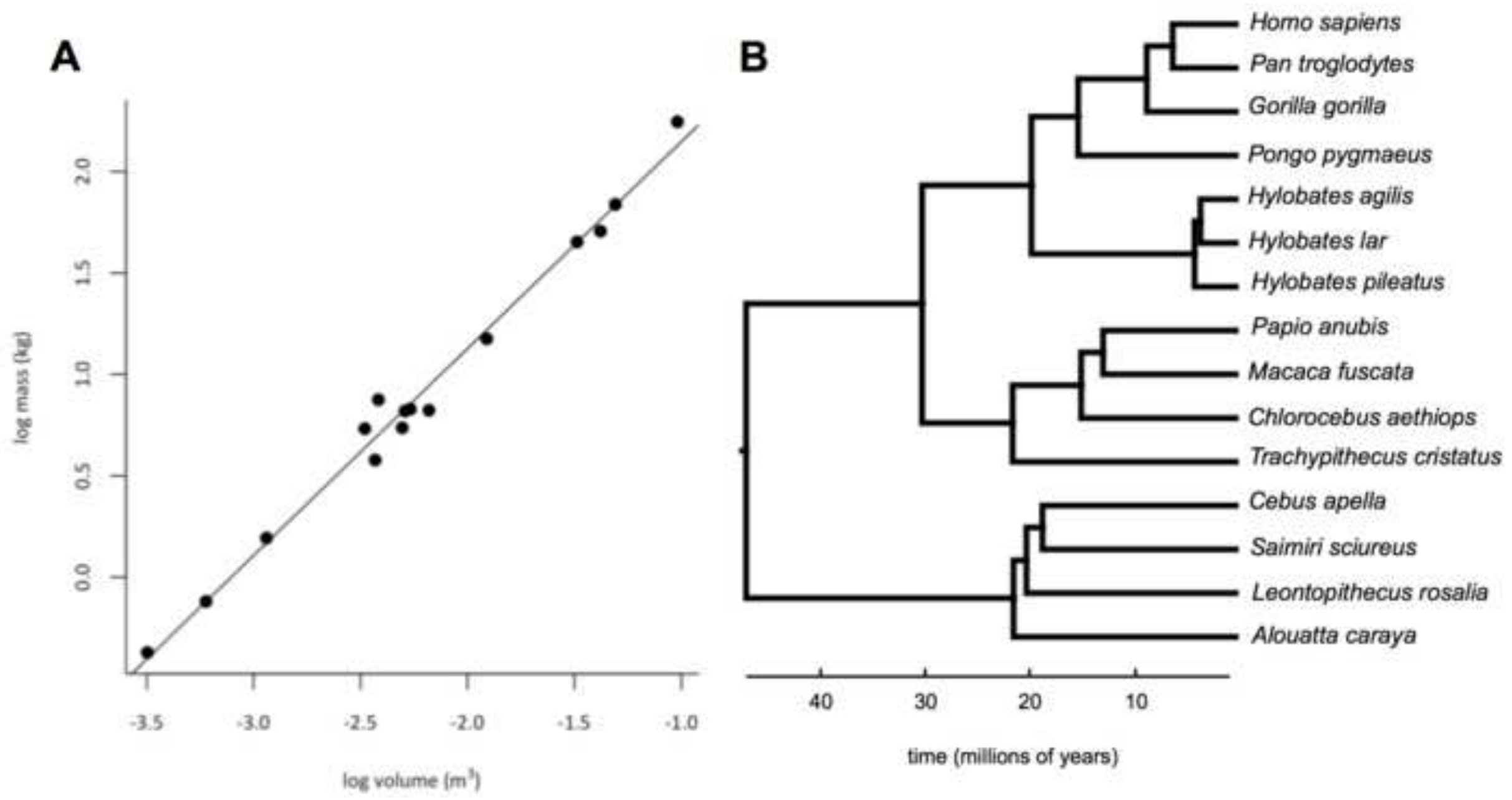
Figure7
Click here to download high resolution image

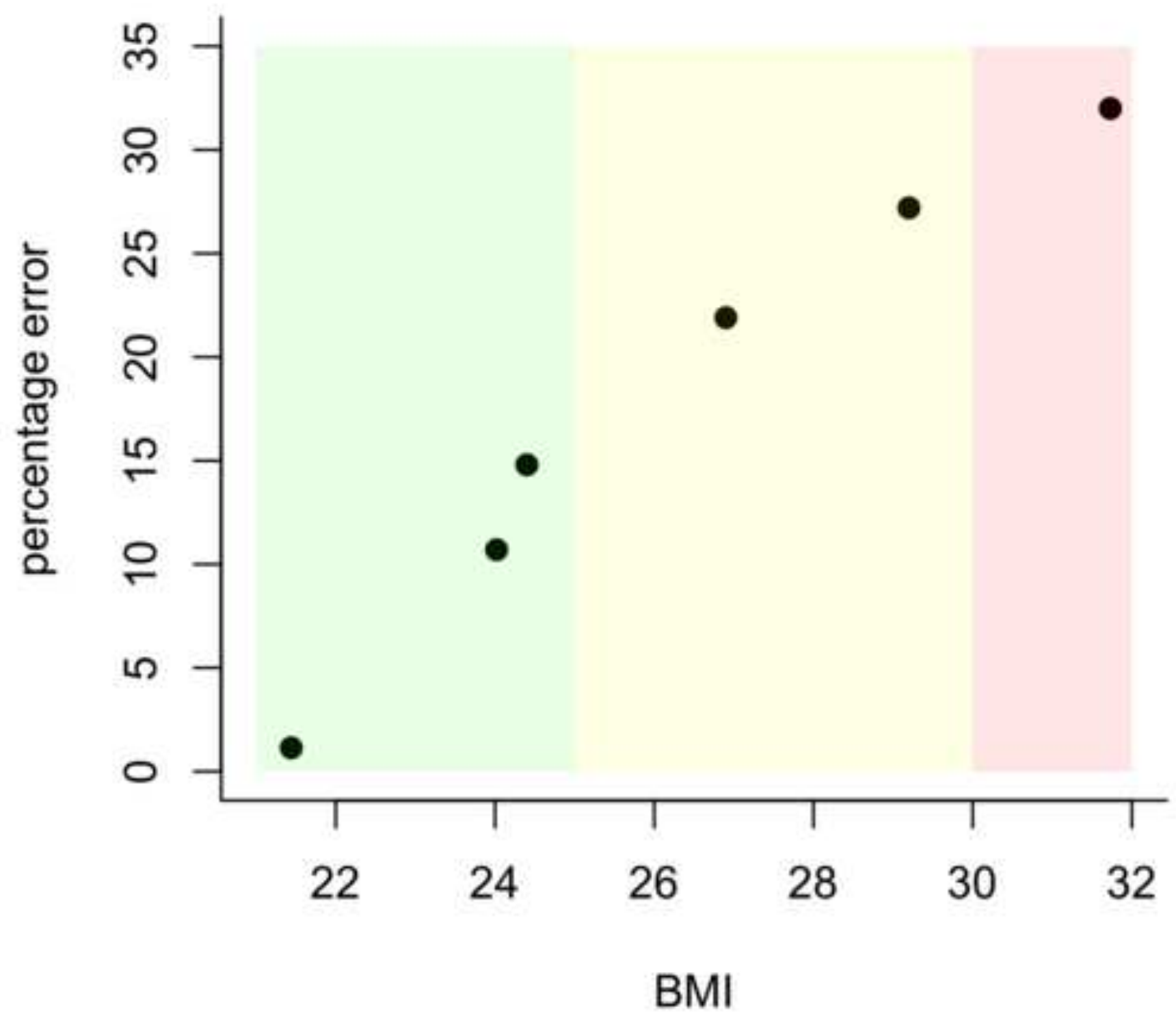


Click here to download high resolution image
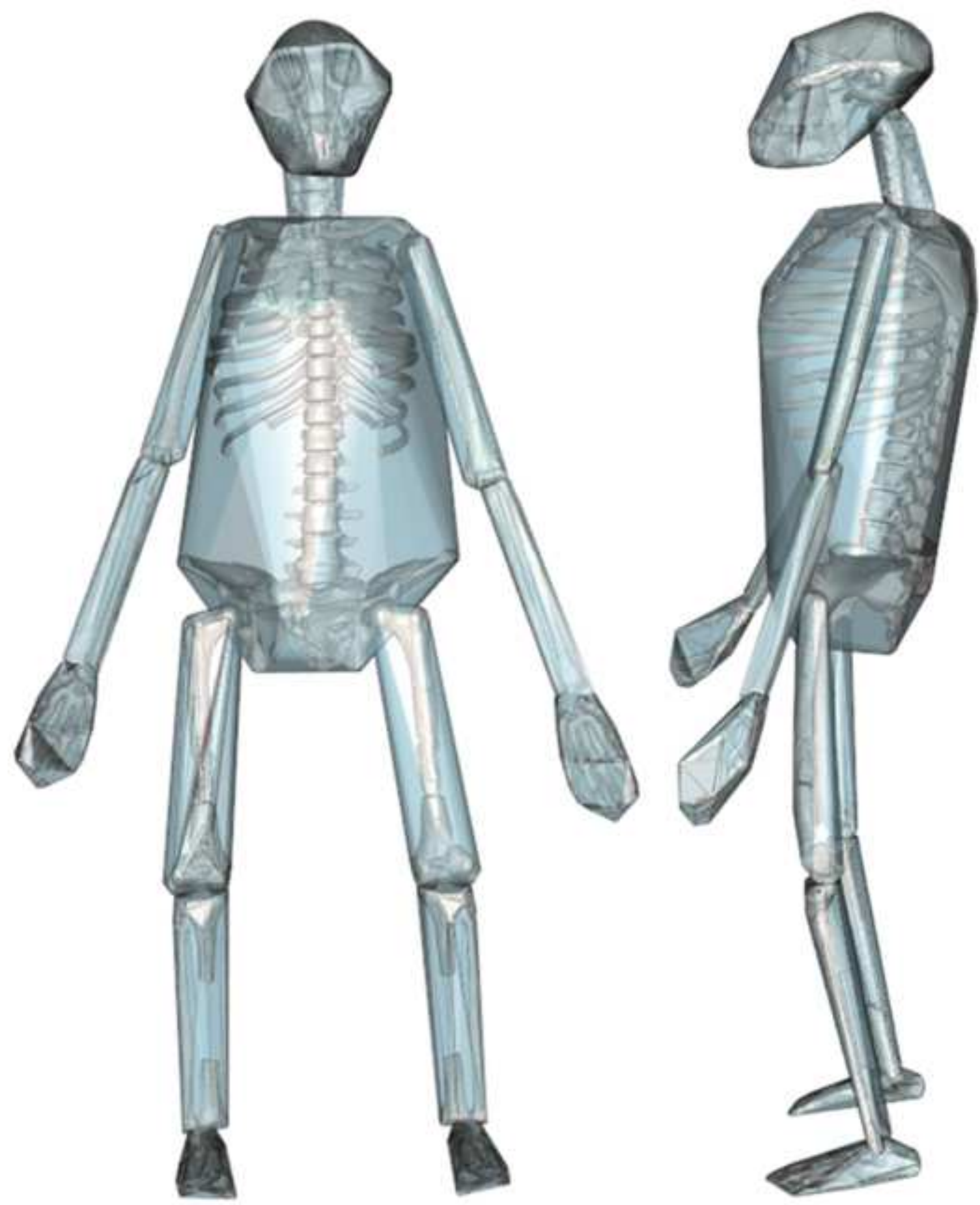
Click here to download high resolution image
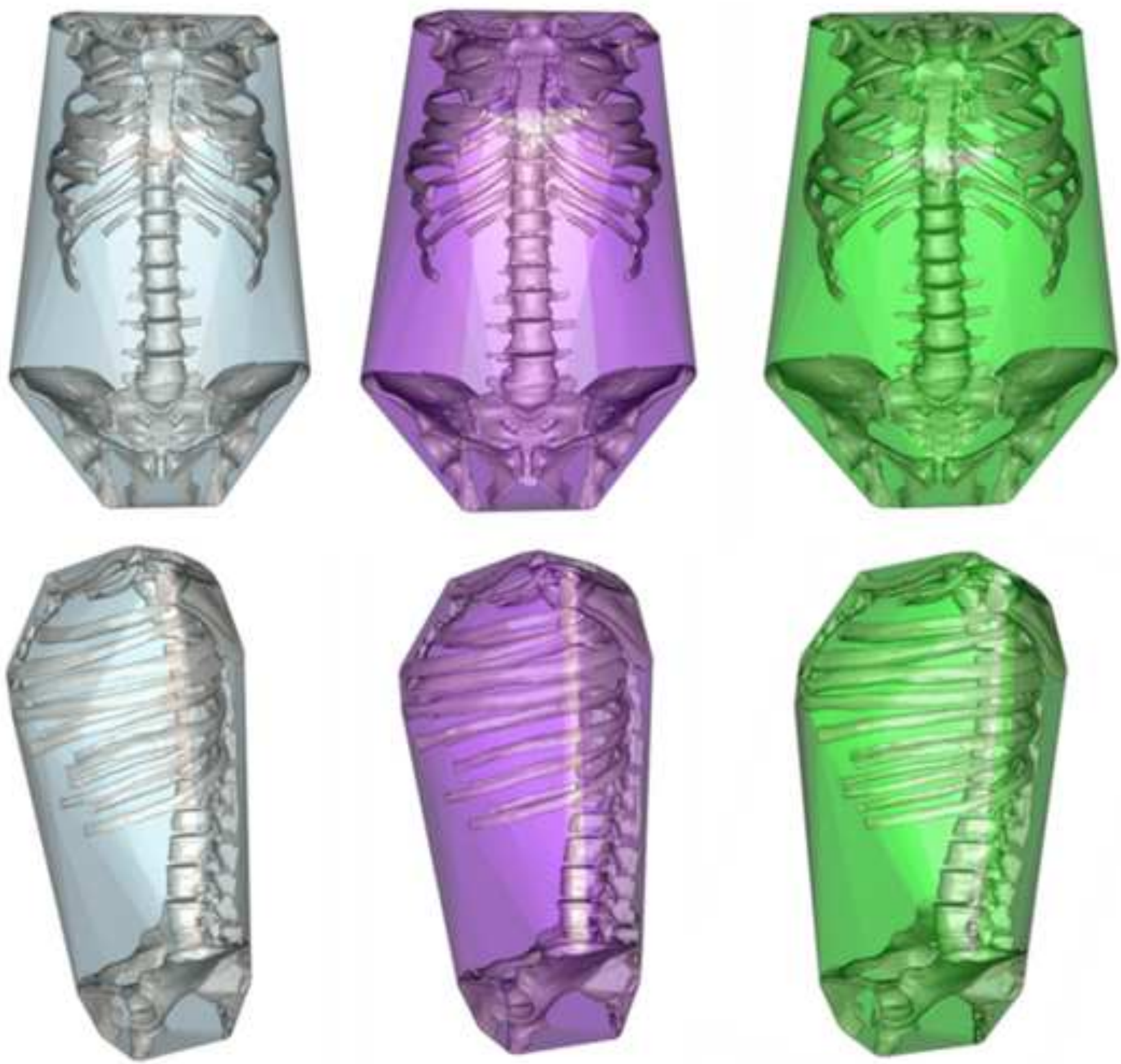
Supplementary Material
Click here to download Supplementary Material: SupplementaryMaterial merged-done.docx

C.

(2)

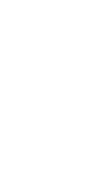

(1)

$\sqrt{10}$

(1)

(1) (1) . . . . . . . . . . . . 